\title{
THEORETICAL EVALUATION OF R22 AND R502 ALTERNATIVES
}

Final Report

$$
\begin{aligned}
& \text { RECEEIVED } \\
& \text { JUN } 101993 \\
& \text { OSTI }
\end{aligned}
$$

Piotr A. Domanski and David A. Didion

\author{
Building Environment Division \\ National Institute of Standards and Technology \\ U.S. Department of Commerce \\ Gaithersburg, Marlyand 20899
}

January 1993

\author{
Prepared for \\ The Air-Conditioning and Refrigeration Technology Institute \\ Under \\ ARTI MCLR Project Number 650-50900
}

\begin{abstract}
This researeb project is supported, in whole or in part, by U.S. Department of Energy grant aumber DE-FC02-91CE23810: Materials Compatibility and Lubricants Research (MCLR) on CFC-Refrigerant Substintes. Federal funding supporting this project constiuntes $93.67 \%$ of allowable costs. Funding from non-governmeat sources supporting this project consists of direct cost sharing of $6.33 \%$ of allowable costa; and in-kind contributions from the air-conditioning and refrigeration industry.
\end{abstract}




\section{DISCLAIMER}

The U.S. Department of Energy's and the air-conditioning industry's support for the Materials Compatibility and Lubricants Research (MCLR) program does not constitute an endorsement by the U.S. Department of Energy, nor by the air-conditioning and refrigeration industry, of the views expressed herein.

\section{NOTICE}

This report was prepared on account of work sponsored by the United States Government. Neither the United States Government, nor the Department of Energy, nor the Air-Conditioning and Refrigeration Technology Institute, nor any of their employees, nor of any of their contractors, subcontractors, or their employees, makes any warranty, expressed or implied, or assumes any legal liability or responsibility for the accuracy, completeness, or usefulness of any information, apparatus, product or process disclosed or represents that its use would not infringe privately-owned rights.

\section{COPYRIGHT NOTICE}

(for journal publication submissions)

By acceptance of this article, the publisher and/or recipient acknowledges the right of the U.S. Government and the Air-Conditioning and Ref-igeration Technology Institutes, Inc. (ARTI) to retain a nonexclusive, royalty-free license in and to any copyrights covering this paper. 
ARTI MCLR Project Number 650-50900

\title{
THEORETICAL EVALUATION OF R22 AND R502 ALTERNATIVES
}

\author{
Piotr A. Domanski and David A. Didion
}

\begin{abstract}
The report presents the performance evaluation of nine $R 22$ alternatives and three R502 alternatives. The study was conducted using a semi-theoretical model, CYCLE-11, with a pure cross-flow representation of heat transfer in the evaporator and condenser. The Carnahan-Starling-DeSantis equation of state was used for calculating thermodynamic properties. Transport properties were not involved in the simulations.

Simulations were conducted for "drop-in" performance, for performance in a modifled system to assess the fluids' potentials, and for performance in a modified system equipped with a liquid-line/suction-line heat exchanger. The results - presented on a relative basis to R22 and R502 performance - include the volumetric capacity, coefficient of performance, pressure increase across the compressor, and compressor discharge pressure and temperature.
\end{abstract}

\section{SCOPE}

The evaluation of nine R22 alternative fluids was performed at two cooling and two heating operating conditions that represent $35.0^{\circ} \mathrm{C}\left(95^{\circ} \mathrm{F}\right), 27.8^{\circ} \mathrm{C}\left(82^{\circ} \mathrm{F}\right)$, $8.3^{\circ} \mathrm{C}\left(47^{\circ} \mathrm{F}\right)$, and $-8.3\left(17^{\circ} \mathrm{F}\right)$ temperature rating points for a residential heat pump [1]. The R22 alternatives considered in this study are: R32/125 (60/40), R32/125/134a/290 (20/55/20/5), R32/125/134a (10/70/20) and (30/10/60), R290, R32/227ea (35/65), R32/134a (25/75) and (30/70), and R134a.

Three R502 alternatives were evaluated at one operating condition typical for commercial refrigeration installations. The heat-transfer-fluid temperature entering the evaporator and condenser was $-23.3^{\circ} \mathrm{C}\left(-10^{\circ} \mathrm{F}\right)$ and $35^{\circ} \mathrm{C}\left(95^{\circ} \mathrm{F}\right)$, respectively. The evaluated $R 502$ alternatives are: $R 32 / 125 / 143 a(10 / 45 / 45)$, R125/143a (45/55), and R125/143a/134a (44/52/4).

This study is restricted to the thermodynamic merits only and does not concern itself with other attributes like transport properties, toxicity, and flammability. The pure cross-flow representation of the evaporator and condenser used in these simulations makes the results of this study most applicable to systems equipped with cross-flow heat exchangers.

This is the only and final report covering the study performed. 


\section{SIGNIEICANT RESULTS}

\section{INTRODUCTION}

Due to an implication in the destruction of the stratospheric ozone layer, chlorine-containing refrigerants are scheduled for phase-out by the Montreal Protocol and subsequent regional regulations. Chlorofluorocarbons (CFCs), which are characterized by a high ozone depletion potential (ODP), are slated for complete production phase-out in the United States by the end of 1995 . For hydrochlorofluorocarbons (HCFCs), the 1992 revision of the Montreal Protocol stipulates the first production ceiling for the year 1996 and the final elimination in 2030 .

In response to the phase-out regulations, the Air-Conditioning and Refrigeration Institute (ARI) established the Alternative Refrigerants Evaluation Program (AREP) to pool together efforts of ARI member companies in search of alternative fluids for R22 (HCFC-22) and azeotropic mixture R502 (48.8\% HCFC-22 and 52.2\% (FC-115). The objective of this report is to provide a computer evaluation of alternative refrigerants and refrigerant mixtures. This evaluation is restricted to thermodynamic merits only and does not concern itself with other attributes like transport properties, toxicity, or flammability.

\section{Impact of Fluld Properties on System Performance - General Remarks}

To better understand the results presented in this report, let's briefly recite why different fluids exhibit different performance in a given application. The reason lies in their different thermodynamic and transport properties. Although all properties are important, some are more important than others.

In the thermodynamic properties category, the most important parameters are the normal boiling point temperature - or related to it critical temperature $\left(T_{c r}\right)$ and heat capacity. Figure 1 depicts the impact of the critical temperature by
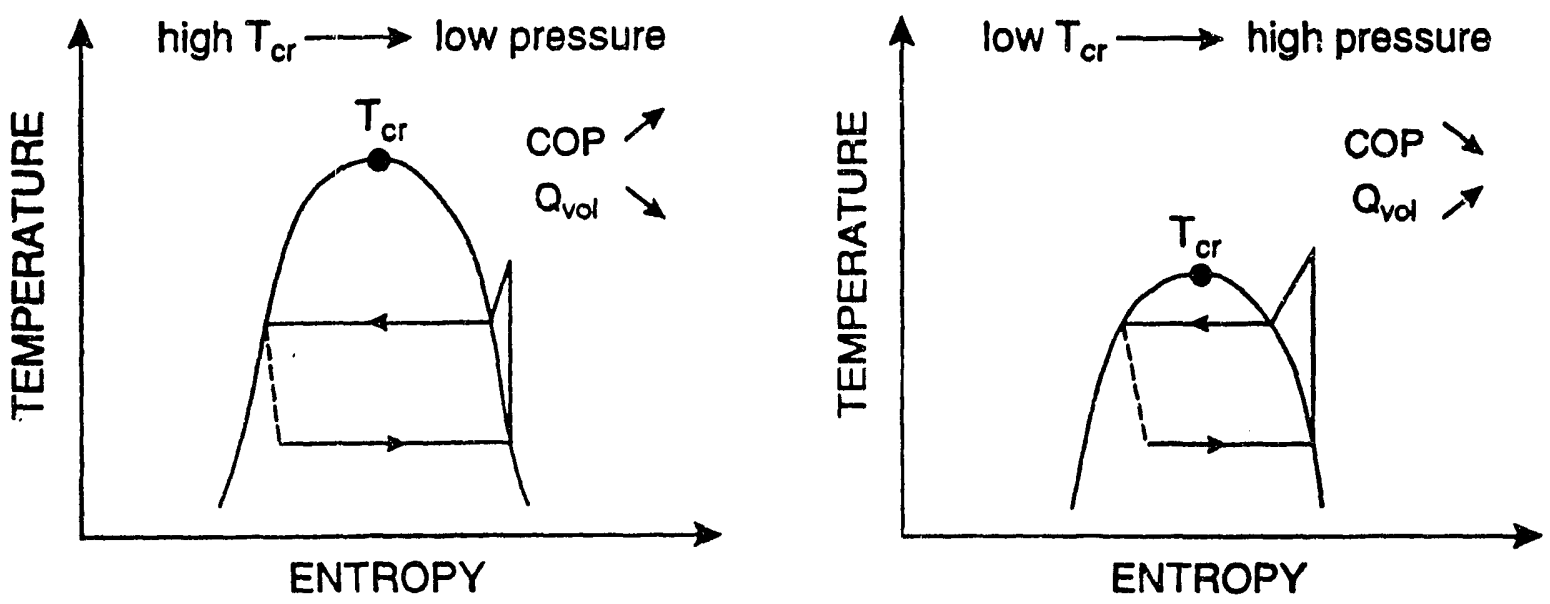

Figure 1. Impact of critical temperature on cycle performance. 


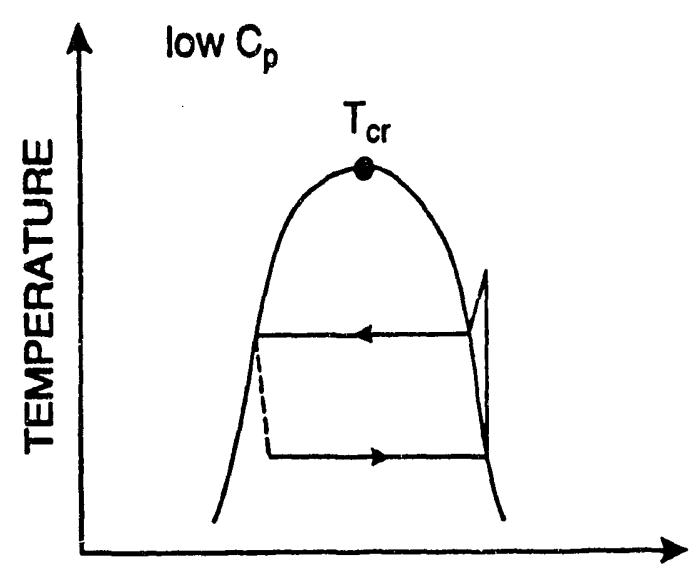

ENTROPY

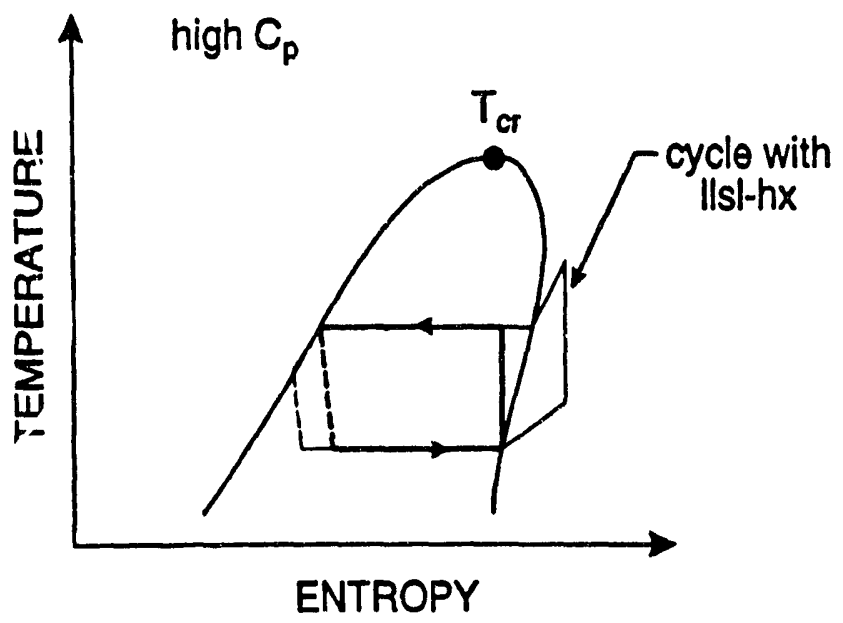

Figure 2. Impact of heat capacity on refrigeration cycle

showing a reversed Rankine cycle realized by two different fluids. The more volatile fluid (lower $T_{c r}$ ) starts evaporation at a higher vapor quality and has a larger superheated vapor horn - both attributes contribute to a lower coefficient of performance (COP). However, this refrigerant will have a higher volumetric capacity $\left(Q_{v o l}\right)$ since a lower critical temperature results in a higher pressure at the compressor inlet. Thus, the trade-off between the COP and volumetric capacity is unavoidable; a fluid that exceeds another fluid in volumetric capacity will most likely have a lower COP. It may be noted that differences in volumetric capacity are much sharper than differences in the COP.

Heat capacity affects performance profoundly through its impact on the outline of the two-phase dome. A refrigerant with a high heat capacity has its two-phase

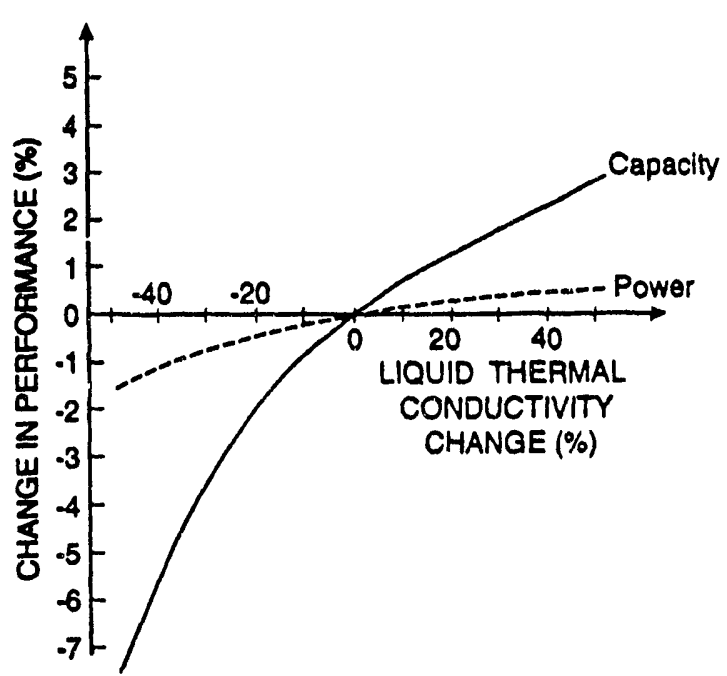

Figure 3. Impact of liquid thermal conductivity on performance of air-toair heat pump

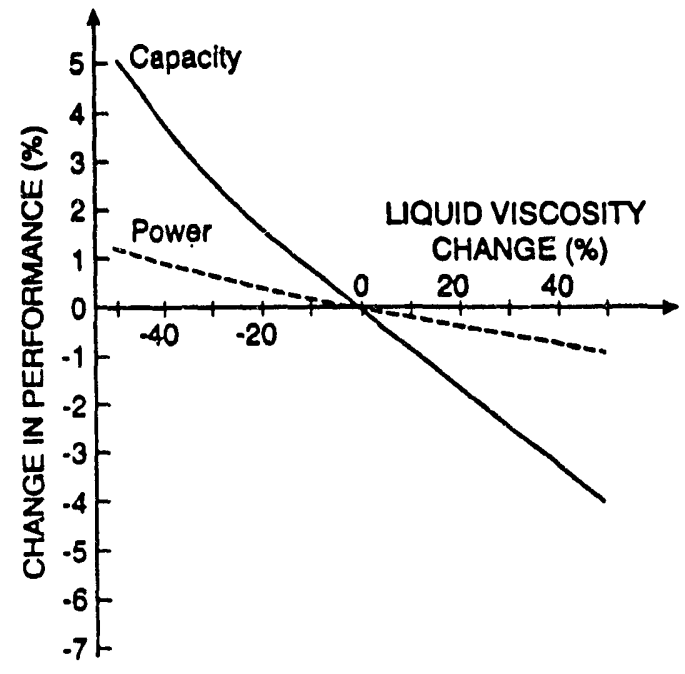

Figure 4. Impact of liquid viscosity on performance of air-to-air heat pump 
dome skewed to the right, which may result in significant flashing losses and undesirable "wet compression", as showed in Figure 2. A cycle with a liquidline/suction-line heat exchanger (llsl-hx) - shown by a thin line on the diagram for high-heat-capacity fluid - is relieved from these undesirable conditions and may have a better COP than a basic reverse Rankine cycle [2].

The impact of transport properties will vary with the heat exchanger effectiveness, heat transfer surfaces, and with a heat transfer resistance on the side of heat transfer fluids (HTFs). For an air-to-air heat pump charged with R22 and employing a smooth-tube evaporator and condenser, liquid thermal conductivity and viscosity were found to be most influential, as showed in Figures 3 and 4 taken from reference [3]. These figures are provided only to allow estimation of the influence of liquid thermal conductivity and viscosity; transport properties are not involved in the following performance evaluations.

\section{Performance Compar1son Methods: "Drop-In" vs. Equal Heat Exchanger Loading}

We have to distinguish between two basic methods for performance comparison of different fluids:

1. "drop-in" evaluation, and

2. evaluation at a constant heat exchanger loading.

In the "drop-in" method, a new refrigerant is evaluated in a machine designed for the original refrigerant (the expansion device may be modified to assure the same subcooling at the condenser outlet). This is a typical first-cut test performed in a laboratory. "Drop-in" testing, although telling us the performance we may expect in a given machine, does not give us a fair comparison between the fluids. This lack of objectivity results from the changed system capacity when the same system is charged with refrigerants having different volumetric capacities. Different system capacities cause different heat fluxes through the evaporator and condenser resulting in different temperatures in the condenser and the evaporator for transfer of heat to/from the heat transfer fluids, if the heat exchangers remain the same, as is assumed.

The second, more objective comparison methodology (McLinden and Radermacher [4]) requires a constant ratio of capacity to the total heat transfer area (evaporator plus condenser) for all the fluids analyzed. This requirement - difficult to implement in laboratory testing but easy to impose in computer simulations assures the same heat exchanger area loading despite differences in volumetric capacity between refrigerants studied.

The second approach is more objective; however, "drop-in" applications are also of interest. Since both approaches have their merits, this study includes both "drop-in" simulations and simulations in modified equipment at the same heat flux through the evaporator and condenser.

\section{DISCLAIMER}

This report was prepared as an account of work sponsored by an agency of the United States Government. Neither the United States Government nor any agency thereof, nor any of their employees, makes any warranty, express or implied, or assumes any legal liability or responsibility for the accuracy, completeness, or usefulness of any information, apparatus, product, or bility for the accuracy, completeness, or usefulness of any information, apparatus, product, or ence herein to any specific commercial product, process, or service by trade name, irademark, manufacturer, or otherwise does not necessarily constitute or imply its endorsement, recommendation, or favoring by the United States Government or any agency thereof. The views and opinions of authors expressed herein do not necessarily state or reflect those of the Uniled States Government or any agency thereof. 


\section{Modeling Tools}

Three semi-theoretical cycle models, derived from CYCLE-11 [5] and described in Appenaix $B$, were used to perform simulations. The models do not include transport properties; they carry the implicit assumption that transport properties (and the overall heat transfer coefficients) are the same for the fluids studied. With the understanding of the assumptions involved, our confidence in the CYCLE-11 programs was established through various joint laboratory/simulation projects, e.g. the study of R22, R32/134a, and R32/152a [6].

Thermodynamic properties are represented in the cycle models through the Carnahan-Starling-DeSantis (CSD) equation of state, as implemented in the REFPROP package [7]. Not all pure fluids considered in this study and their interaction coefficients are included in REFPROP. The needed data for fluids not covered by REFPROP were obtained from $G$. Morrison [8].

It has to be noted that the CSD equation of state does not accurately represent highly polar fluids like $R 32$, which is included in this report. The CSD equation of state was the only option available to us. A new REFPROP version based on the Carnahan-Starling-DeSantis-Morrison (CSDM) equation of state [9] - a CSD successor that can handle polar refrigerants - did not cover all the needed fluids at the time of this study.

\section{EVALUATION OF R22 ALTERNATIVES}

R22 alternatives were evaluated at conditions approximating two cooling and heating rating points for residential heat pumps [1]. These conditions, represented by temperatures of the heat transfer fluids (air), are shown in Table 1. R22 alternative fluids considered in this study are shown in Table 2 . The thermodynamic data included in Table 2 were obtained from REFPROP. Refrigerant 22 - specified as fluid number 0 - was used for reference purposes in presenting the simulation results.

\section{"Drop-In" Evaluation}

(Unchanged System, Constant Heat Exchangers)

"Drop-in" simulations were performed using CYCLE-11.UA, which requires selecting (pre-coding) a system to be simulated, similar to "drop-in" tests in a laboratory where a certain heat pump has to be selected for testing. In the case of CYCLE11. UA, a compressor, condenser and evaporator must be designated.

A physical description of the compressor is needed, which, at the minimum, requires the compressor swept volume and RPM as input. From two options available for the compressor simulation, a more detalled representation of a hermetic compressor was selected for "drop-in" runs, which required specification of the electric motor efficiency, polytropic efficiency, and pressure drop and heat transfer parameters for the processes taking place between four key locations within a hermetic compressor [Appendix B]. The values for these parameters were selected to obtain pressure drop and temperature change typical 
Table 1. Inlet and Outlet Temperatures of Heat Transfer Fluid (Air) used for Evaluating R22 and R502 Alternatives

\begin{tabular}{||l|c|c|c|c|c|}
\hline \multirow{4}{*}{} & \multicolumn{4}{|c|}{ R22 } & R502 \\
\cline { 2 - 6 } & \multicolumn{2}{|c|}{ Cooling } & \multicolumn{2}{c|}{ Heating } & Refrigerating \\
\cline { 2 - 6 } & ${ }^{\circ} \mathrm{C}$ & ${ }^{\circ} \mathrm{C}$ & ${ }^{\circ} \mathrm{C}$ & ${ }^{\circ} \mathrm{C}$ & ${ }^{\circ} \mathrm{C}$ \\
& $\left.{ }^{\circ} \mathrm{F}\right)$ & $\left({ }^{\circ} \mathrm{F}\right)$ & $\left({ }^{\circ} \mathrm{F}\right)$ & $\left(^{\circ} \mathrm{F}\right)$ & $\left({ }^{\circ} \mathrm{F}\right)$ \\
\hline Condenser Inlet & 35.0 & 27.8 & 21.1 & 21.1 & 35 \\
& $(95)$ & $(82)$ & $(70)$ & $(70)$ & $(95)$ \\
\hline Condenser Outlet & 43.2 & 37.4 & 32.5 & 28.1 & 40.6 \\
& $(110)$ & $(99.3)$ & $(90.5)$ & $(82.6)$ & $(105)$ \\
\hline Evaporator Inlet & 26.7 & 26.7 & 8.3 & -8.3 & -23.3 \\
& $(80)$ & $(80)$ & $(47)$ & $(17)$ & $(-10)$ \\
\hline Evaporator Outlet & 14.4 & 13.8 & 2.7 & -11.3 & -27.2 \\
& $(58)$ & $(56.8)$ & $(36.9)$ & $(11.7)$ & $(-17)$ \\
\hline
\end{tabular}

for R22 at a $35^{\circ} \mathrm{C}\left(95^{\circ} \mathrm{F}\right)$ temperature test. The value of 0.9 was selected for both the electric motor efficiency and polytropic efficiency. The chosen values for the two efficiencies and pressure and heat loss parameters resulted in an overall "black-box" polytropic efficiency of approximately 0.7 .

The evaporator and condenser were simulated as pure cross-flow heat exchangers, and were represented by their respective overall conductances, $U A_{\text {, }}$ and $U A_{c}$. The values for $\mathrm{UA}_{\text {, }}$ and $\mathrm{UA}_{\mathrm{c}}$ were selected such that $7.8^{\circ} \mathrm{C}\left(46^{\circ} \mathrm{F}\right)$ and $46.1^{\circ} \mathrm{C}\left(115^{\circ} \mathrm{F}\right)$ refrigerant saturation temperatures at the evaporator and condenser outlet, respectively, were obtained at R22 simulations at the $35^{\circ} \mathrm{C}\left(95^{\circ} \mathrm{F}\right)$ test condition. Additionally, the following parameters were imposed as constants in all simulation runs:

- zero degree of vapor superheat at the evaporator outlet,

- zero degree of liquid subcooling at the condenser outlet,

- $34.5 \mathrm{kPa}$ (5 psi) pressure drop in the evaporator,

- $34.5 \mathrm{kPa}$ ( $5 \mathrm{psi}$ ) pressure drop in the condenser.

Once a heat pump was defined, simulations were performed at four operating conditions listed in Table 1 . Note that the assumption of the constant temperature profile of air in "drop-in" simulations implies different mass flow of air, depending on the capacity of the system charged with a particular refrigerant. The impact of a resulting changes in the air-side heat transfer coefficient and fan powers are not considered by the simulation model.

Five indicators of performance were selected for presenting the simulation results: capacity, COP, pressure increase across the compressor, compressor discharge pressure, and compressor discharge temperature. All results are presented on a relative scale with respect to performance of $R 22$. 


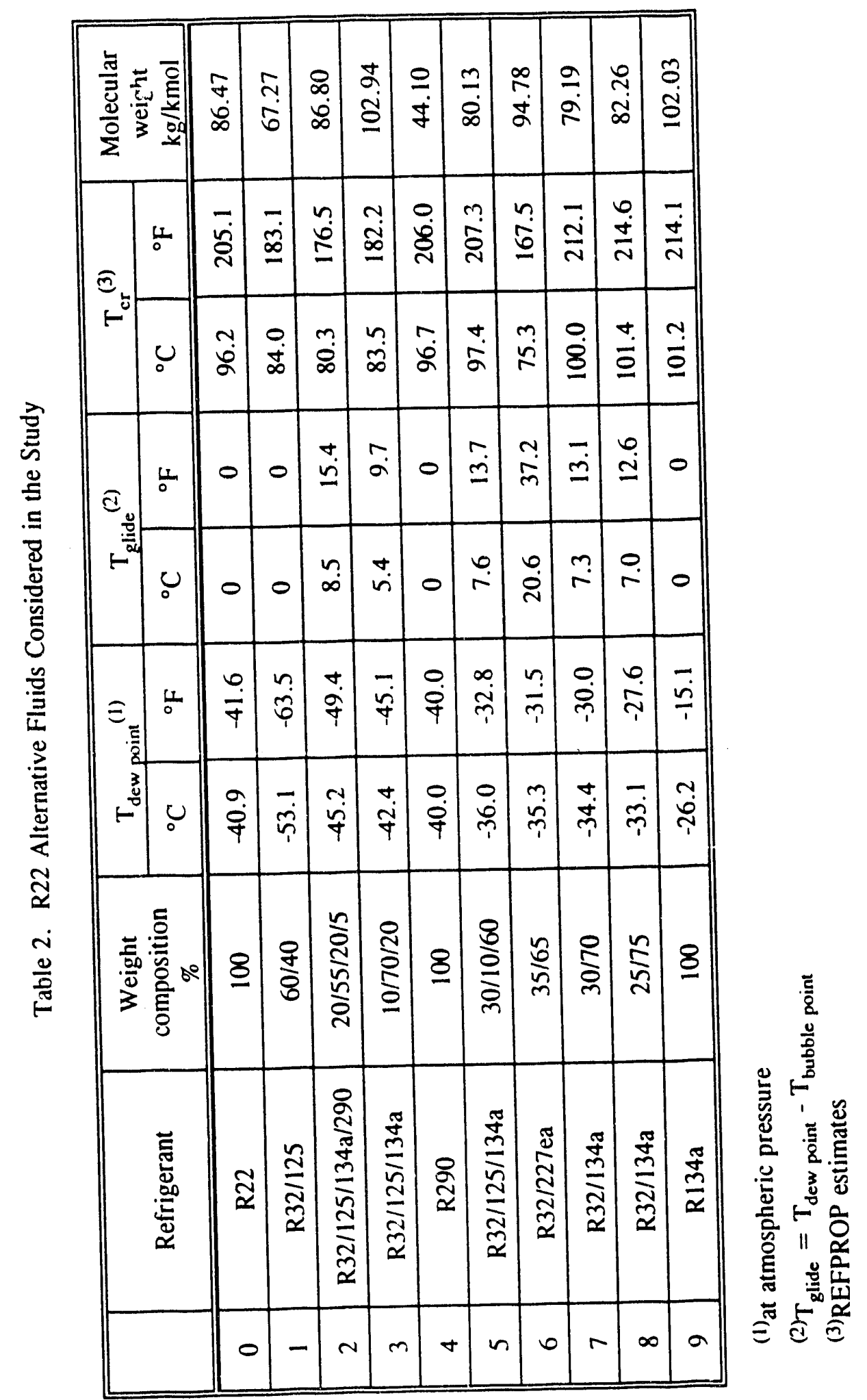




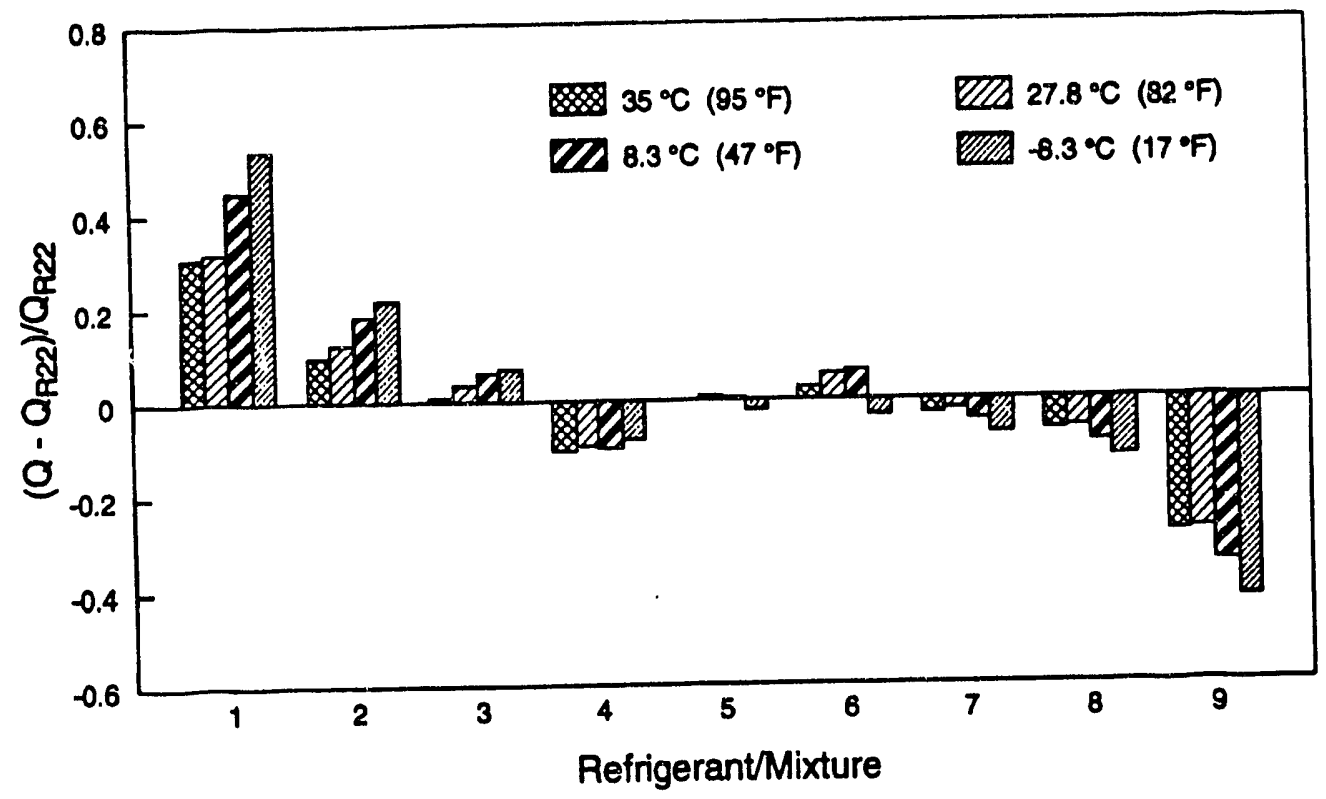

Figure 5. Volumetric capacity for "drop-in" simulations

Figure 5 shows a difference in capacity between candidate fluids and R22 divided by the capacity of R22. The four bars shown for each fluid represent results at four operating conditions denoted on the figure by the temperature of air entering what would be the outdoor coil - a customary designation of operating conditions for residential heat pumps.

The results are consistent with basic expectations relating volumetric capacity to refrigerant pressure. The highest pressure fluid, R32/R125 mixture (非), has the highest capacity, while the lowest pressure fluid, R134a (非9), has the lowest capacity. The range of capacity difference for the screened fluids with respect to $R 22$ is almost \pm 50 percent.

Figure 6 shows a difference in COPs on a relative basis. If we imposed this figure over Figure 5 , we could notice that refrigerants having a lower capacity display a higher COP than R22. We may notice that the difference in COP is not as large as the difference in capacity; in the extreme cases the COP difference does not exceed \pm 20 percent.

Figure 7 presents the difference in pressure increase across the compressor between the candidate fluids and R22 divided by the value for R22. The results presented in this figure are indicative of the forces carried by the compressor bearings. A general trend in Figure 7 is consistent with the trend displayed in Figure 5: higher capacity fluids exhibit a higher pressure increase across the compressor because they operate at higher reduced temperatures, at which $\mathrm{dP} / \mathrm{dT}$ gradient at saturation is greater. We can observe the same pattern in Figure 8 , which shows the difference in discharge pressures. Significant differences for high pressure fluids with respect to R22 (for example, over $1200 \mathrm{kPa}$ (174 psi) for fluid 非] indicate possible safety problems if those fluids are tested in unmodified R22 equipment. 


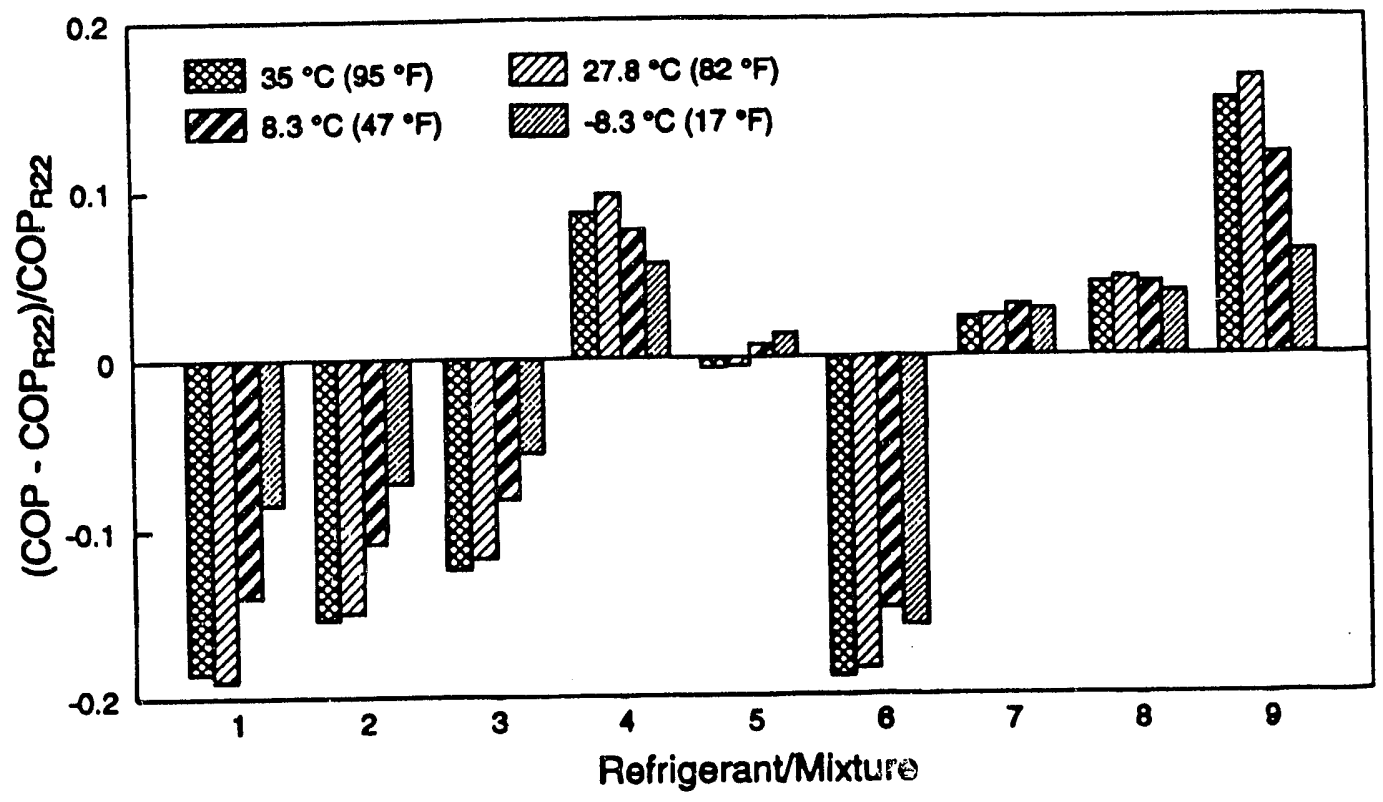

Figure 6. Coefficient of Performance for "drop-in" simulations

Figure 9 displays a difference between compressor discharge temperature for candidate fluids and R22. This information is useful in the consideration of lubricant and refrigerant stability. Except for fluid $\|_{1}$, all remaining refrigerants had a lower discharge temperature than R22.

In addition to the above simulation results, it is of interest to examine the average temperature in the evaporator since this temperature is a measure of the dehumidification capability of the fluid considered. As shown in Figure 10,

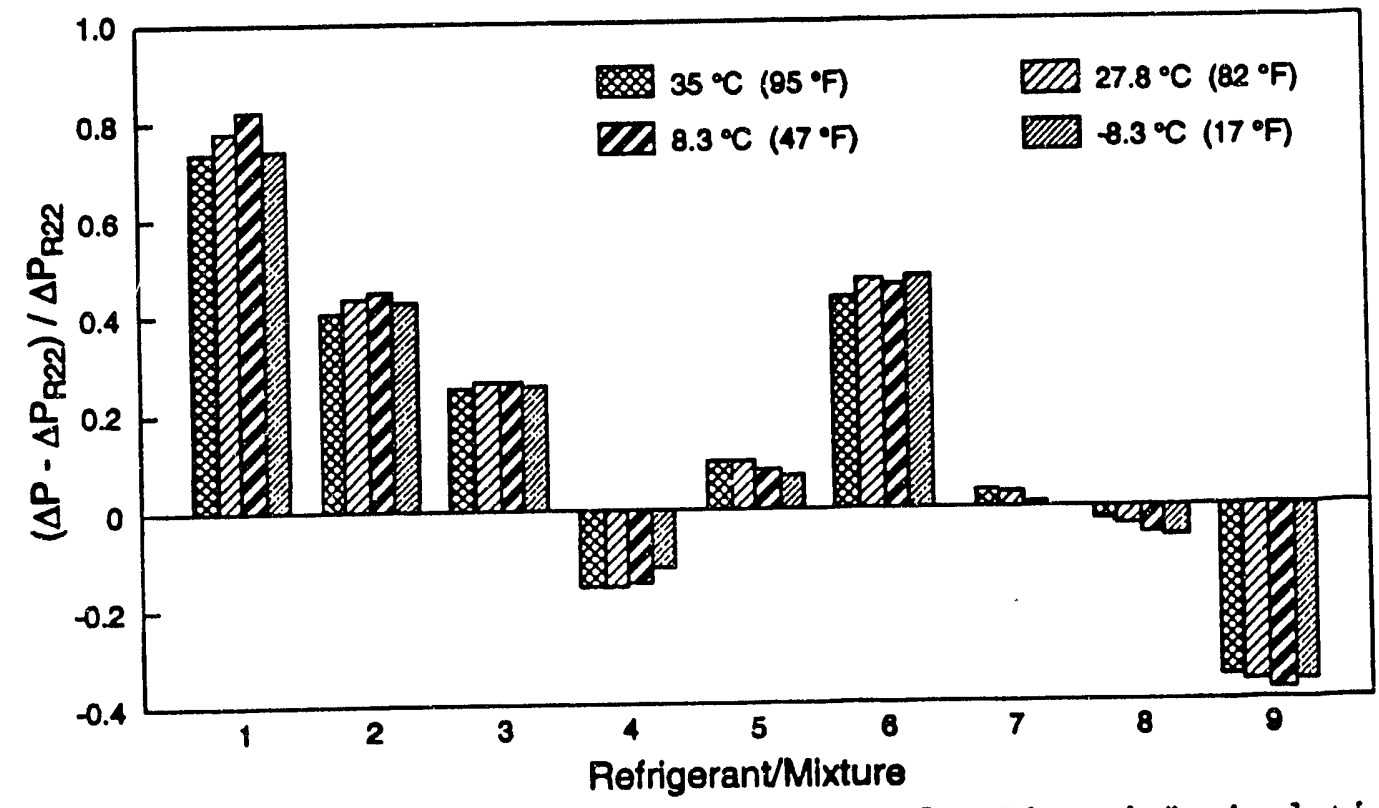

Figure 7. Pressure increase across compressor for "drop-in" simulations 


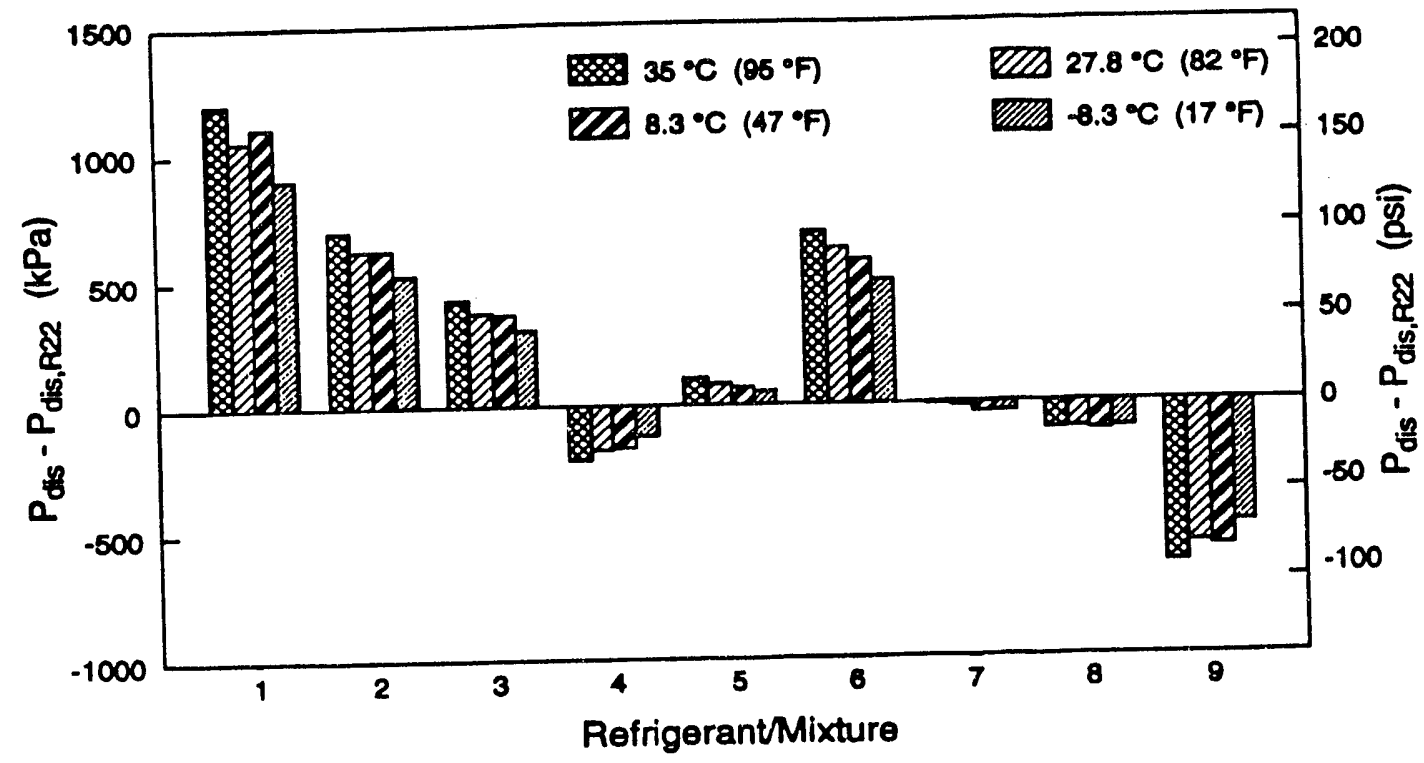

Figure 8. Compressor discharge pressure for "drop-in" simulations

temperatures different from R22 were observed - from a high pressure R32/R125 mixture having the lowest average temperature to a pure R134a having the highest average temperature, exceeding $10^{\circ} \mathrm{C}\left(50^{\circ} \mathrm{F}\right)$.

"Drop-in", constant-heat-exchanger-area simulations provide us with information concerning "drop-in" performatce; however, these simulations do not facilitate an objective comparison. For example, a lower-pressure, lower-capacity fluid (like R134a) will work at a smaller temperature difference between the condenser

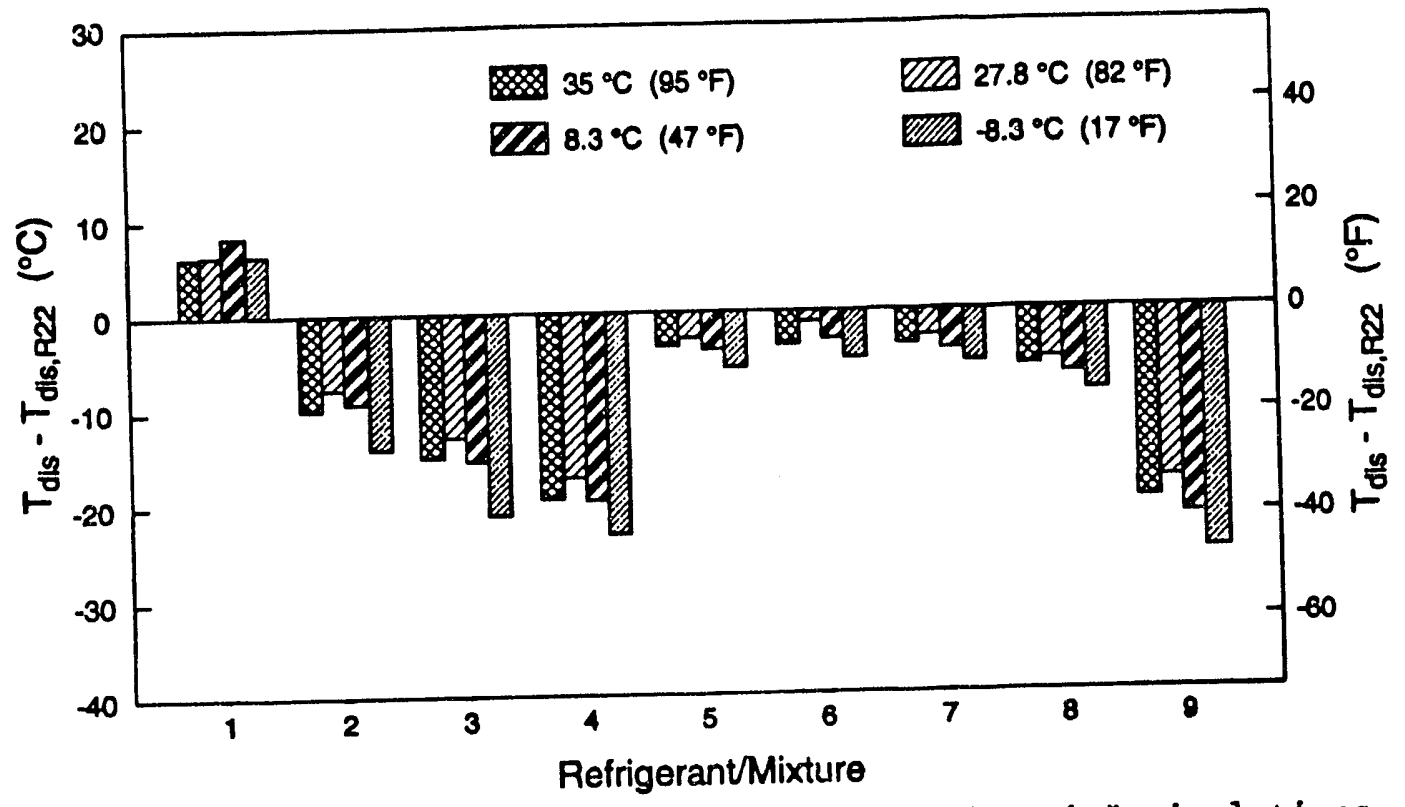

Figure 9. Compressor discharge temperature for "drop-in" simulations 


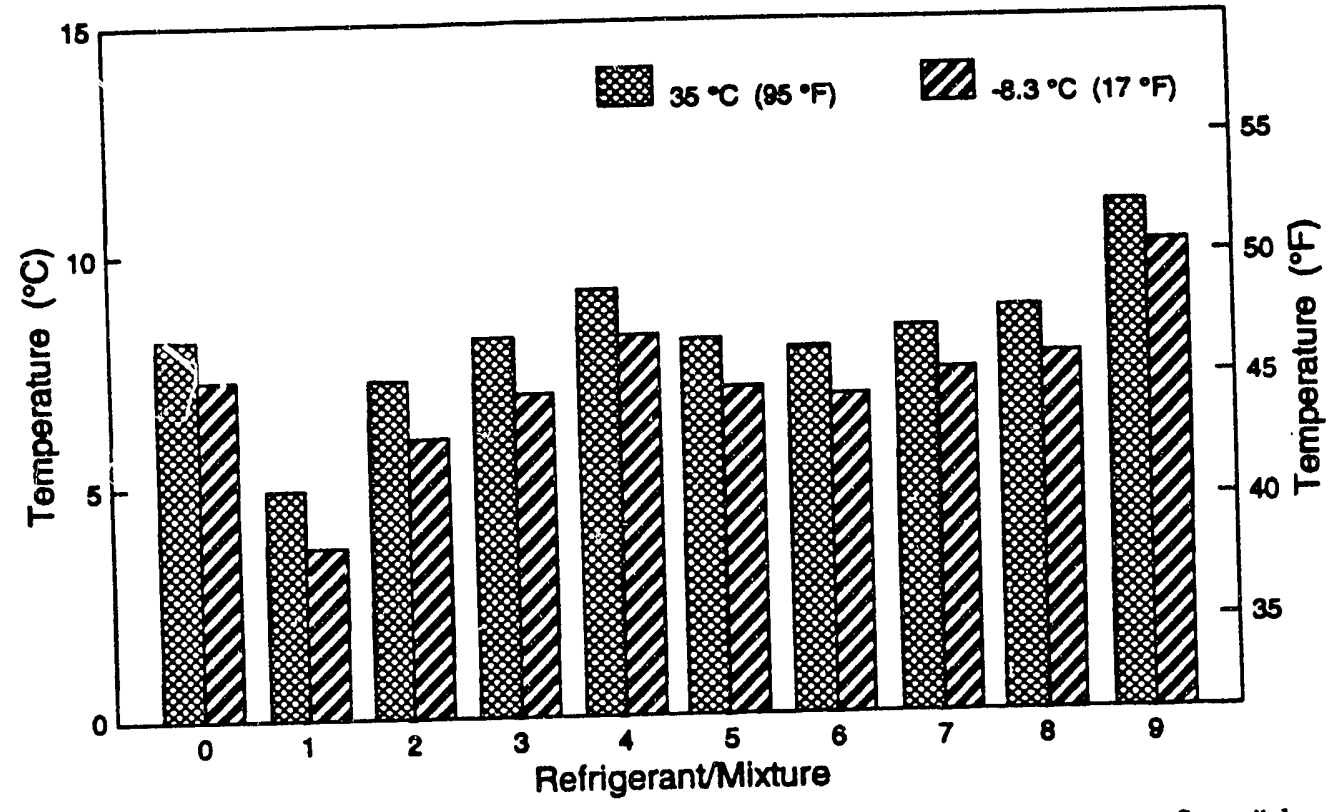

Figure 10. Average refrigerant temperature in the evaporator for "drop-in" simulations

and evaporator than R22 (because less heat has to be transferred). This results in a yet lower capacity and higher COP; 1.e., a constant-heat-exchanger evaluation amplifies the fundamental trade-off between capacity and COP discussed at the beginning of this paper. The opposite COP vs. capacity trend can be noted for higher pressure fluids - with an important distinction that higher evaporator temperatures for lower pressure fluids may result in loss of latent capacity.

Evaluation at Constant Heat Exchangers Loading

(Modified Systems)

The objective of a second round of simulations was to provide a fair performance comparison between the alternative fiuids. In contrast to the "drop-in" simulations where performance of all candidates was simulated using one heat pump, in these simulations a different heat pump was selected (coded) for each refrigerant to simultaneously satisfy the following two constraints at the cooling $35^{\circ} \mathrm{C}\left(95^{\circ} \mathrm{F}\right)$ condition:

$$
\begin{aligned}
\frac{Q_{\bullet}}{U A_{\bullet}+U A_{c}} & =\text { const }=\text { value for } R 22 \\
T_{\text {o.ave }} & =\text { const }=\text { value for } R 22
\end{aligned}
$$

The first constraint assures the same loading of the heat transfer area for each refrigerant. This constraint alone can be satisfied by an infinite number of possible distributions of the heat transfer area between the evaporator and condenser. The second constraint removes this degree of freedom by requiring a specific size of evaporator (represented by $U_{0}$ ) so a predefined value of the average temperature in the evaporator, $T_{0, \text { ave. }}$ is achieved. 
Simulations were performed first for R22 at all four operating conditions using the CYCLE-11.UA mode1. The same thermodynamic cycle assumptions were used as for "drop-in" simulations with a difference in representation of the compressor. The pressure drop and heat loses where lumped together in a lower value of polytropic efficiency $\eta_{p}-0.75$, while the efficiency of electric motor was left unchanged at $\eta_{e}=0.9$.

Once $\mathrm{UA}_{e}+\mathrm{UA}_{c}, \mathrm{Q}_{e}$, and $\mathrm{T}_{0}$,ave were obtained for $\mathrm{R} 22$ from simulation at the $35^{\circ} \mathrm{C}$ $\left(95^{\circ} \mathrm{F}\right)$ condition, a modified system for each candidate fluid was devised that satisfied the outlined criteria. This could have been done using CYCLE-11.UA through iterative selection of $U_{A}$ and $U A_{c}$ at a given, unchanged size of the compressor. In practice, $U_{A}$ and $U_{A}$ were selected using another model from the CYCLE-11 family, CYCLE-11. UADT (explained Appendix B), which explicitly provided the information required. Once $U A$ values were established at the $35^{\circ} \mathrm{C}\left(95^{\circ} \mathrm{F}\right)$ condition for each candidate refrigerant (corresponds to selection of modified systems), simulations at the remaining three test conditions were performed using CYCLE-11.UA.

The simulation results for modified systems are presented in Figures 11 through 15. The results for volumetric capacity shown in Figure 11 are representative of the change in compressor displacement required to attain the capacity of R22. Compared to the results obtained for "drop-in" simulations, capacity differences are larger for modified systems (Figure 11) than for the "drop-in" evaluation (Figure 5). For example, high capacity refrigerant $\# 1$, which exceeded R22 in the "drop-in" evaluation on average by $40 \%$, exceeded R22 in a modified system by over 50\%. Also, a larger difference - in the opposite direction - is observed for low capacity R134a (非). This is understood because the first constraint requires more heat transfer area for a higher capacity fluid, and a larger heat transfer area causes a lower temperature lift. This leads to an even higher capacity for

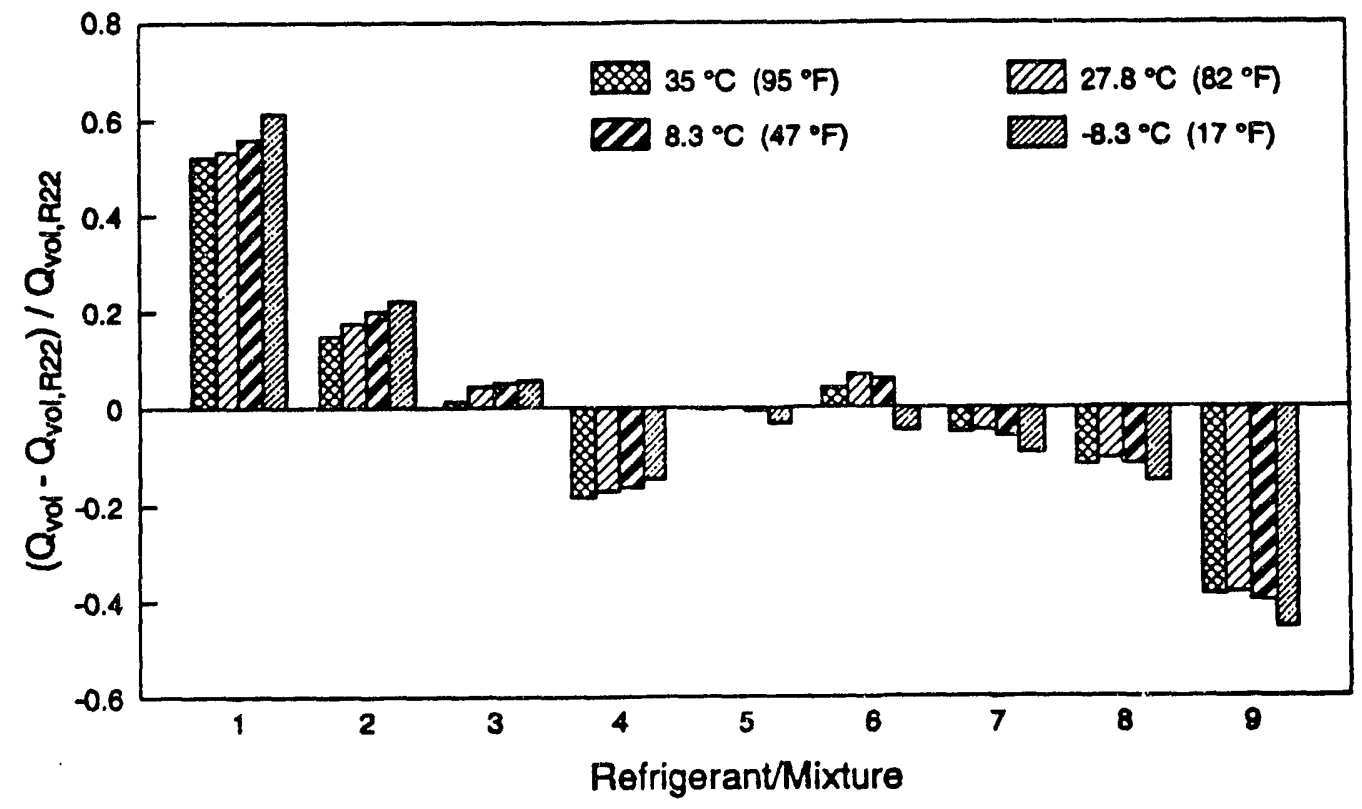

Figure 11. Volumetric capacity for modified systems 


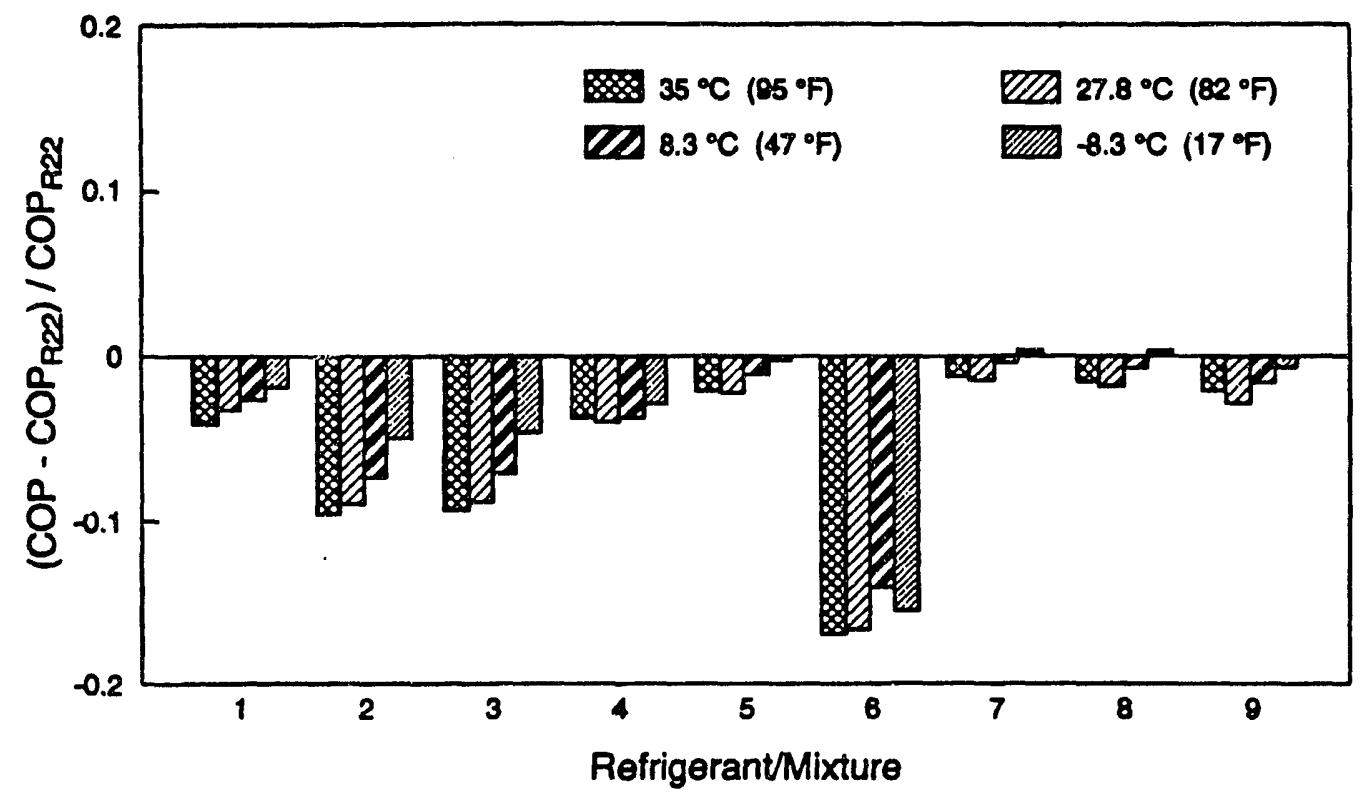

Figure 12. Coefficient of Performance for modified systems

a high capacity refrigerant, such as the R32/R125 mixture (非). The opposite is true for lower capacity refrigerants.

The constant-heat-exchangers-loading criterium also affects the COP. Higher capacity refrigerants attained improved COPs, while lower capacity refrigerants attained lower COPs than found in the "drop-in" simulations. Consequently, the COPs obtained are less different between fluids, as is shown in Figure 12 .

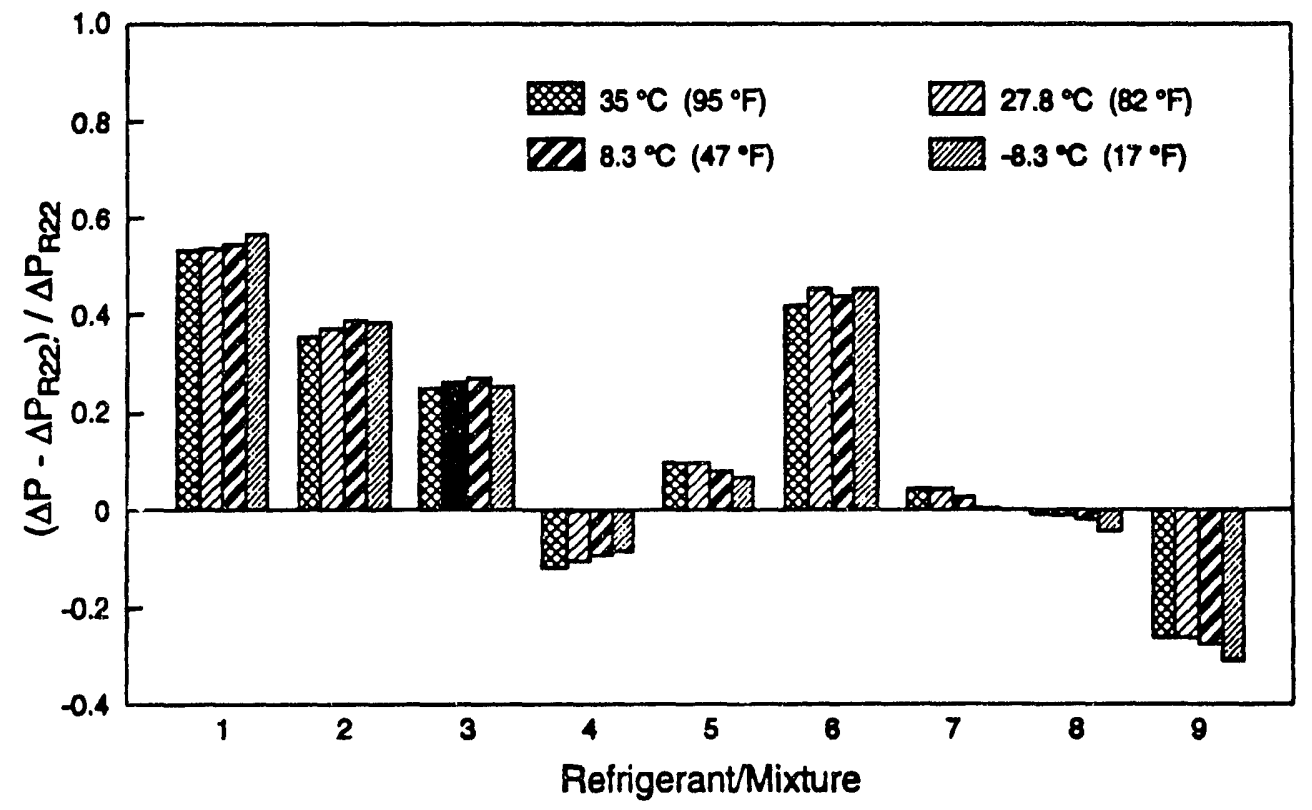

Figure 13. Pressure increase across compressor for modified systems 


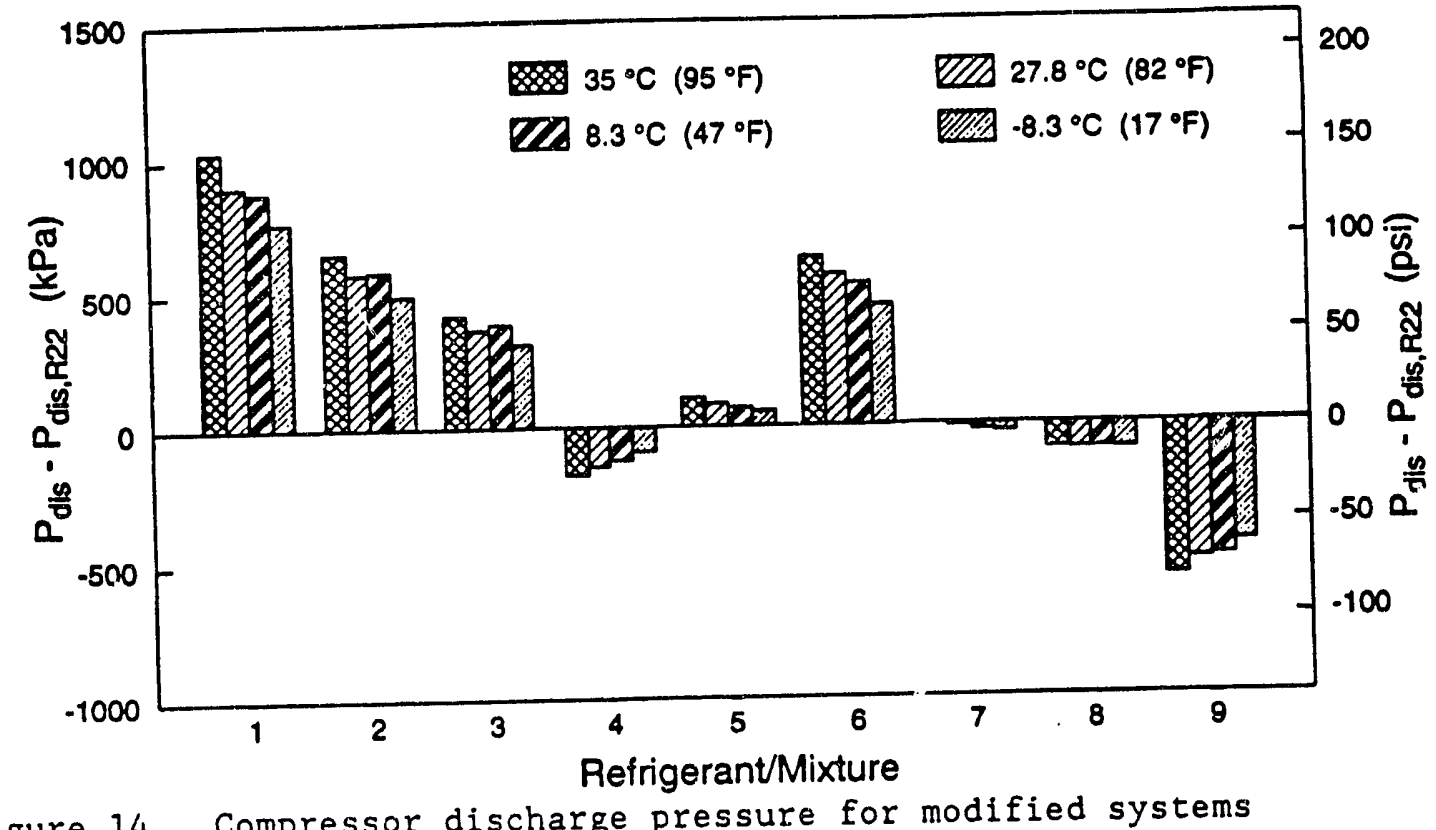

Figure 14. Compressor discharge pressure for modified systems

The disappointing aspect of Figure 12 is that none of the replacement candidates exceeded the COP of R22 at any of the four test conditions. This is even true for the low-pressure/low-capacity R134a for which we expected a better COP - in light of the fundamental COP/capacity trade-off discussed at the beginning of this report. There are two reasons for this sonewhat surprising result. Firstly, the imposition of a constant $34.5 \mathrm{kPa}$ ( $5 \mathrm{psi}$ ) pressure drop for the evaporator and the condenser for all refrigerants causes. low-pressure R134a to experience a larger temperature change than R22, since low-pressure fluids have a larger

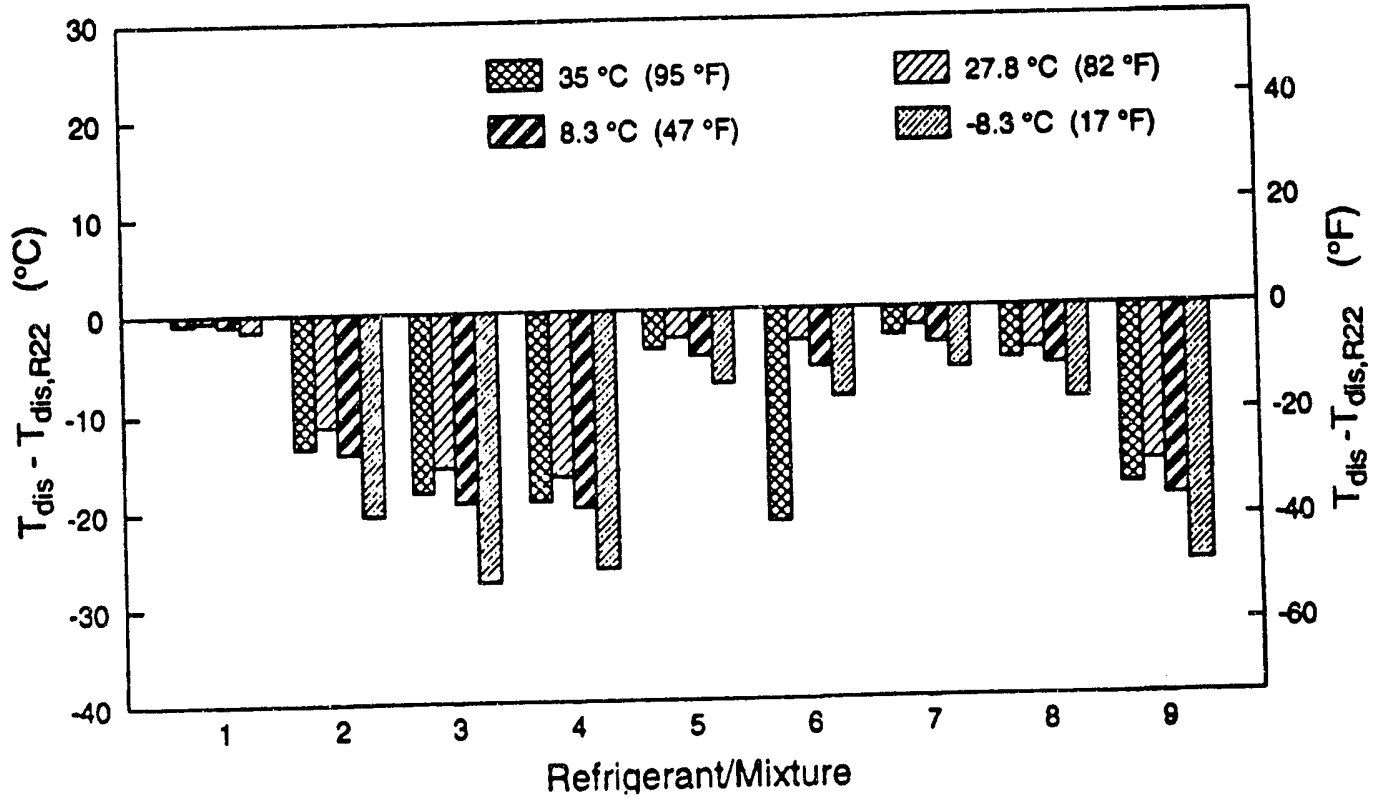

Figure 15. Compressor discharge temperature for modified system 
dT/dP gradient at saturation. Secondly, much higher heat sapacity of R134a makes It a worse performer in a basin reversed Rankine cycle. For simulations with zero pressure drop in the heat exchangers, the COP of R134a would match that of R22.

Refrigerant pressure increase across the compressor, compressor discharge pressure, and compressor discharge temperature - displayed in Figures 13, 14 and 15 - are self-explanatory. It is interesting to note from Figure 15 that the refrigerant discharge temperature for each of the candidate fluids was below the temperature for R22.

Table 3 contains a summary of the simulation results at a constant heat exchanger loading. The numbers in the table are the averages of the results for four operating cunditions shown in Figures 11 through 15.

\section{Impact of a Liquid-Iine/Suction-Line Heat Exchange}

Considering the lower discharge temperature of the alternative refrigerants, additional simulation runs were conducted using the modified systems (as previously defined) equipped with a liquid-line/suction-line heat exchanger (1lsl-hx). This heat exchanger facilitates the heat transfer between a hightemperature liquid refrigerant leaving the condenser and a low-temperature suction vapor leaving the evaporator. The low discharge temperatures of the alternative refrigerants are indicative of their large heat capacities, which suggests performance benefit potential from the application of the 1lsl-hx [2].

Simulation results were performed for one cooling and one heating test condition, $35^{\circ} \mathrm{C}\left(95^{\circ} \mathrm{F}\right)$ and $-8.3^{\circ} \mathrm{C}\left(17^{\circ} \mathrm{F}\right)$, respectively. It was assumed in these simulations that the $11 \mathrm{sl}-\mathrm{hx}$ would increase the suction vapor temperature to $23.9^{\circ} \mathrm{C}\left(75^{\circ} \mathrm{F}\right)$

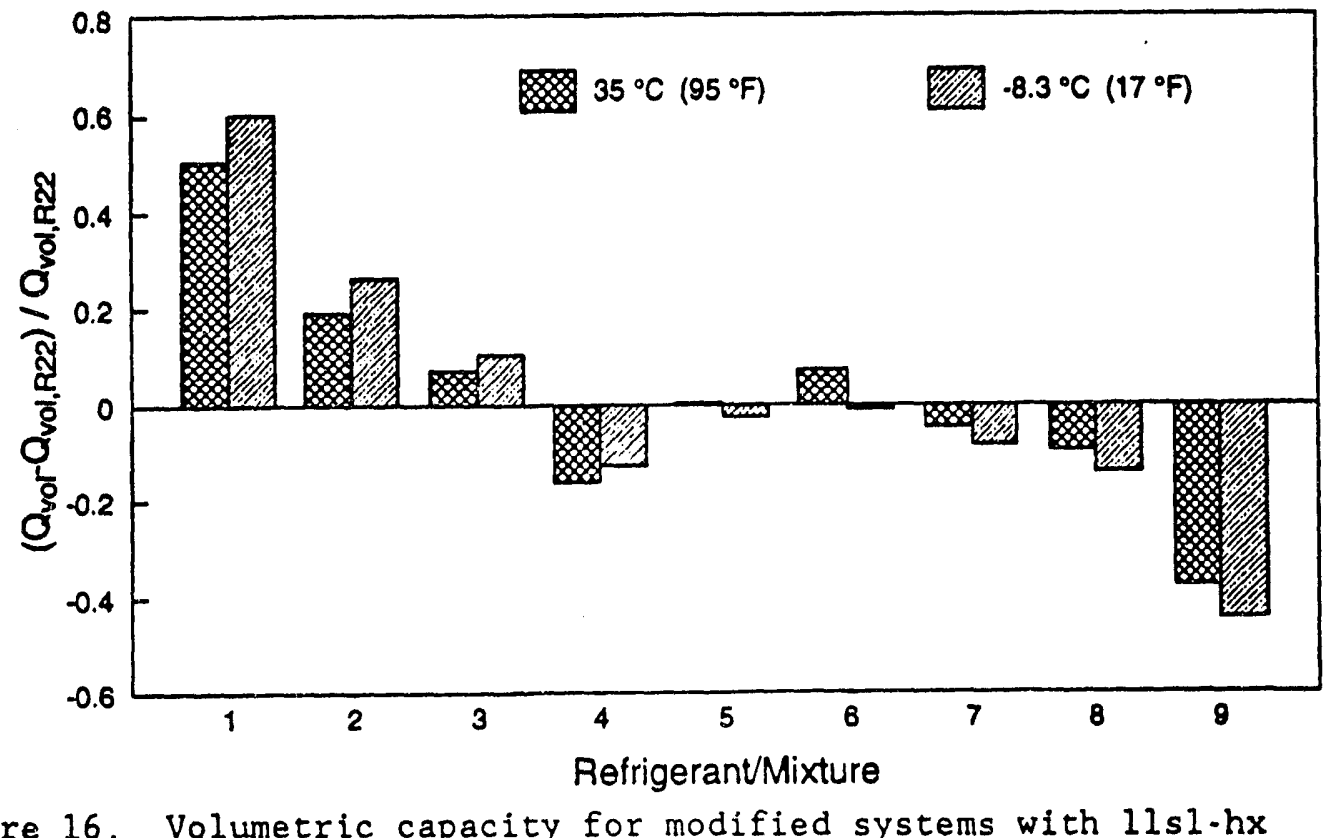

Figure 16. Volumetric capacity for modified systems with 11 sl-hx 


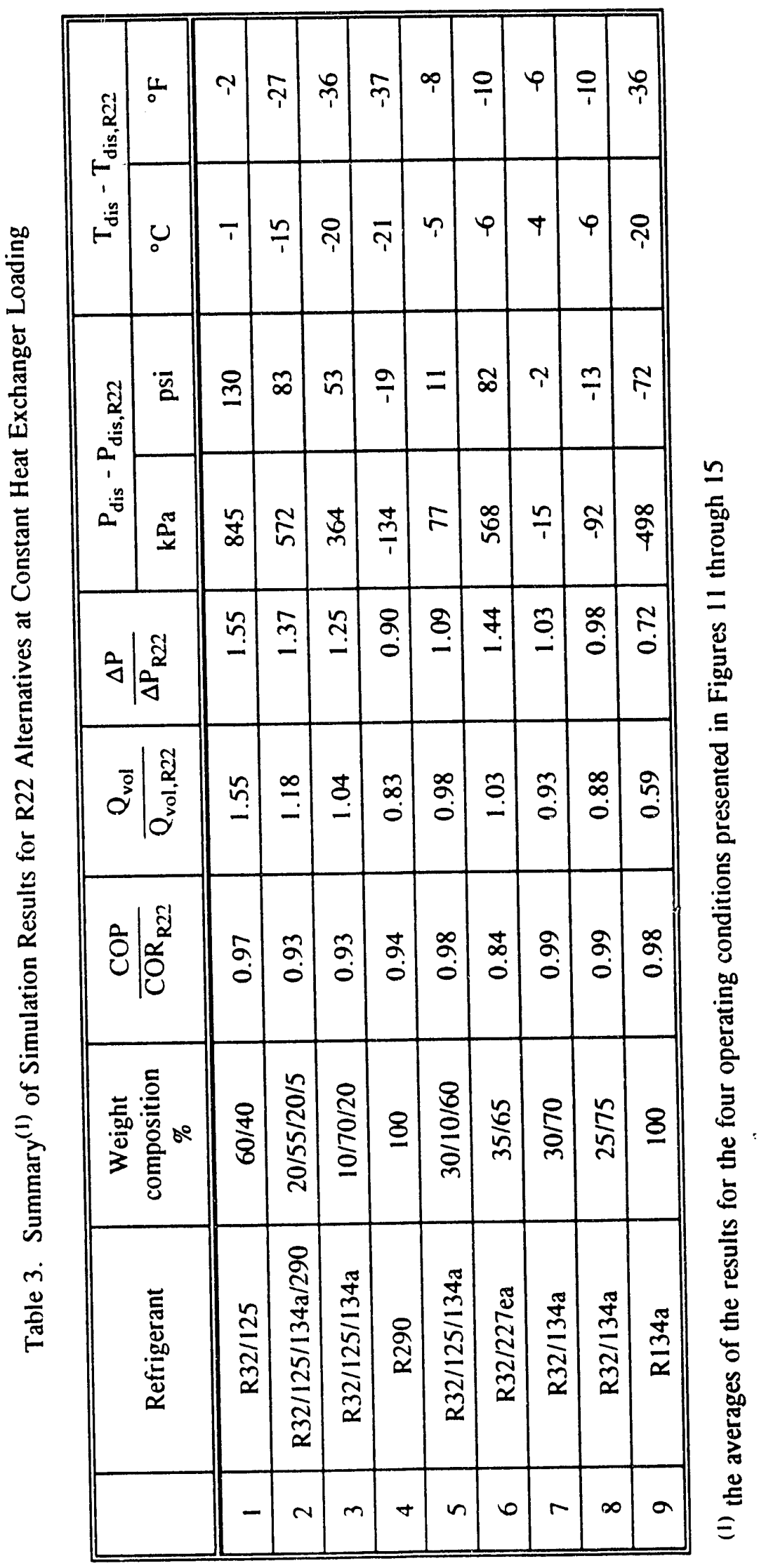




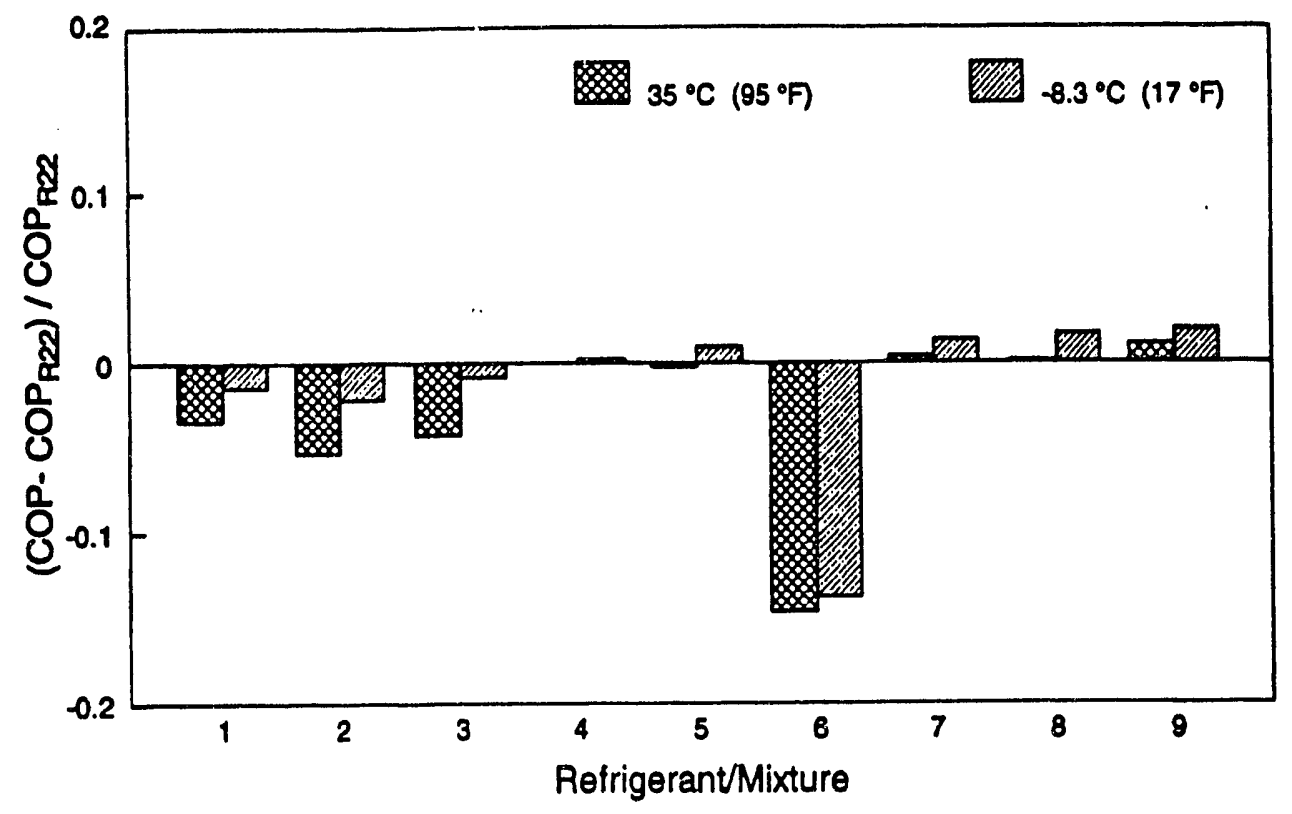

Figure 17. Coefficient of Performance for modified systems with 11sl-hx

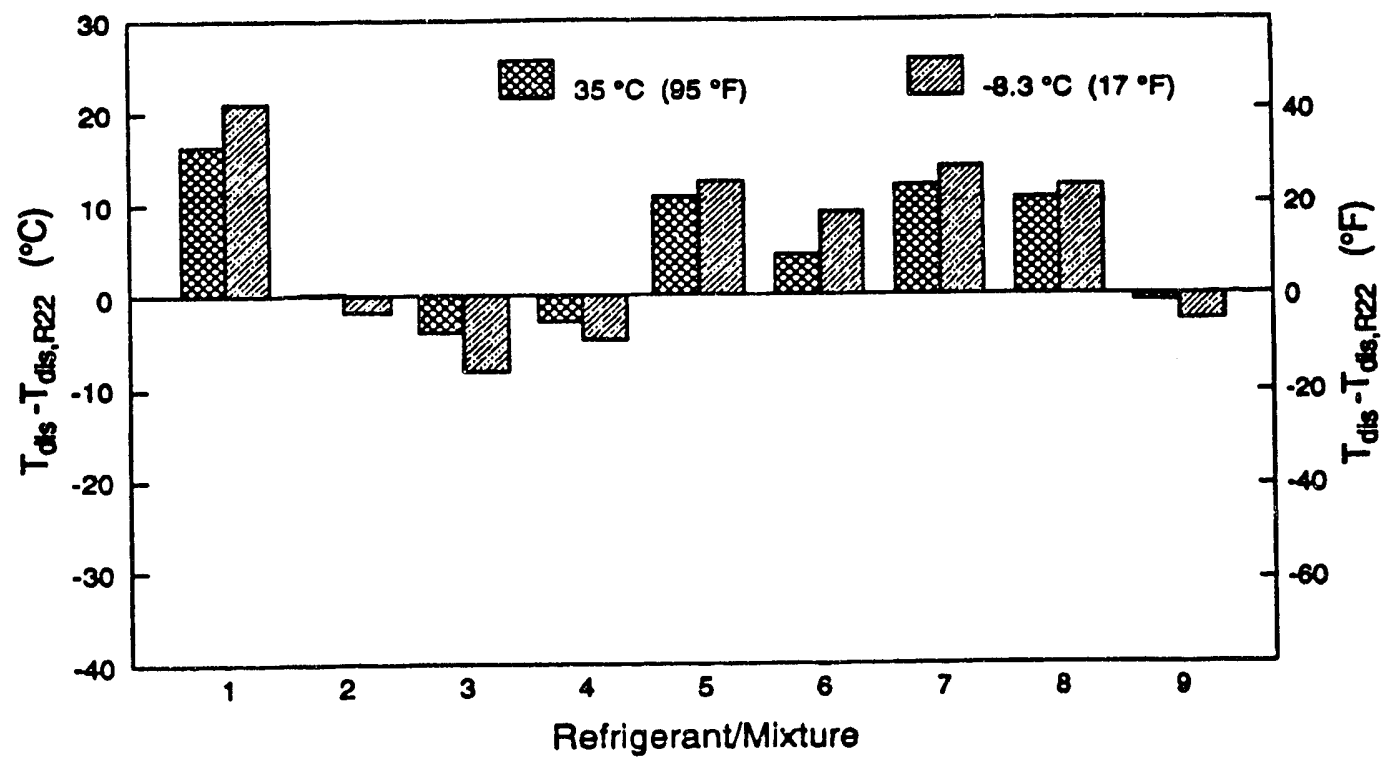

Figure 18. Compressor discharge temperature for modified systems with 11sl-hx

at cooling and to $7.2^{\circ} \mathrm{C}\left(45^{\circ} \mathrm{F}\right)$ at heating. This required a $11 \mathrm{sl}$-hx of approximatiely $45 \%$ effectiveness.

Figures 16, 17, and 18 display simulation results for the volumetric capacity, COP, and compressor discharge temperature. Except to the R32/227ea mixture (非6), the COPs of the examined refrigerants are within 5 percent of $R 22$, some exceeding 
the COP of R22 (R22 did not benefit from the 11sl-hx application). It is interesting to note that the discharge temperatures (Figure 18) are not excessive. This suggests that utilization of the 1lsl-hx may be warranted for some of the alternative refrigerants.

\section{EVALUATION OF R502 ALTERNATIVES}

A popular application for $R 502$ [R22/115 (48.8/51.2)] is in commercial refrigeration. Three refrigerant mixtures, specified in Table 4, were evaluated as alternatives for $\mathrm{R} 502$ at conditions shown in Table 1 .

Evaluation of $\mathrm{R} 502$ alternatives consisted of the same three types of simulations as performed for R22 alternatives:

(1) "drop-in" simulations in a R502 unchanged system,

(2) simulations in modified systems to assure the same loading of the heat exchanger area, and

(3) simulations in modified systems at the same heat exchanger loading and with a liquid-line/suction-line heat exchanger.

All simulations were performed with a pure cross-flow evaporator and condenser imposing $34.5 \mathrm{kPa}$ ( 5 psi) pressure drop for each fluid. Zero degree of subcooling and superheat at the condenser outlet and evaporator inlet, respertively, were assumed. Simulations utilizing the lisl-hx were performed with $70^{\circ} \mathrm{C}\left(158^{\circ} \mathrm{F}\right)$ vapor entering the compressor.

Figure 19 presents simulation results for the three simulation series for a relative volumetric capacity, $\left(Q_{v 01}-Q_{v 01, R 502}\right) / Q_{v 01, R 502}$, a relative Coefficient of Performance, $\left(\mathrm{COP}-\mathrm{COP}_{\mathrm{R} 502}\right) / \mathrm{COP}_{502}$, and relative difference between the compressor

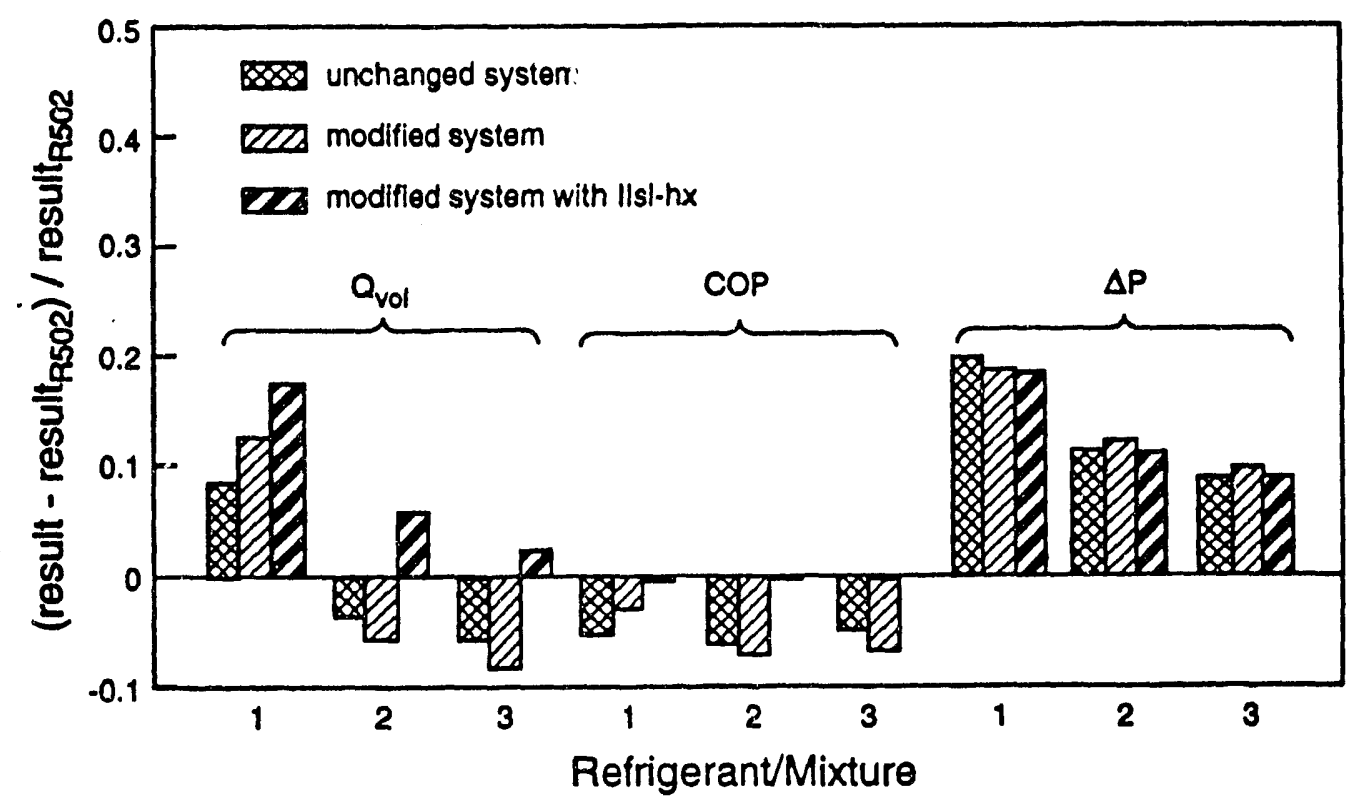

Figure 19. Relative performance of $\mathrm{R} 502$ alternative mixtures 
discharge and suction pressures, $\left(\Delta P-\Delta P_{R 502}\right) / \Delta P_{R 502}$, where $\Delta P$ is the difference between the compressor discharge and suction pressures for a given fluid. The figure shows that the volumetric capacity of mixture (1) exceeds that of R502, while capacity of mixture (2) and (3) is lower if lisl-hx is not employed. Each of the candidate mixtures have a lower COP by a few percents, and have a larger than R502 pressure increase across the compressor by approximately $18 \%$ for mixture (1), 12\% for mixture (2), and $9 \%$ for mixture (3). Also, compressor discharge pressures are higher for the studied alternatives, but compressor discharge temperatures are lower than that for R502. A low discharge temperature of the alternative fluids is very important since $R 502$ has been used in applications in which R22 would have too high temperature in the compressor. The summary of the simulation results at a constant heat exchanger loading is presented in Table 5 .

\section{CONCLUDING REMARKS}

The presented simulation results describe performance of candidate fluids based on the thermodynamic properties. Two basic evaluation approaches were used. The first approach used was the "drop-in" evaluation. The simulation results obtained from this evaluation predict the performance of the candidate refrigerants in a system designed for the original refrigerant - with a possible modification of the expansion device (the same subcooling (zero) at the condenser outlet was assumed at simulations).

The second approach, the constant-heat-exchanger-loading evaluation, provides more objective information on the performance potential of the fluids screened. The simulation results obtained with this approach correspond to a test in a system modified specifically for each refrigerant to obtain the same heat flux through the evaporator and condenser at the design rating point. This simulation constraint assures that the condenser and evaporator pressures are not affected by the different volumetric capacities of the refrigerants studied. In general, higher pressure fluids demonstrated a higher volumetric capacity and a lower COP. A strong exception was the high-glide R32/227ea mixture, of which the performance was penalized by use of pure cross-flow heat exchangers.

Supplementary simulations were performed for the constant-heat-exchanger-loading constraint applying the liquid-line/suction-line heat exchanger. This simulations show that using the llsl-hx may be warranted for some of the candidaţe fluids.

Several assumption were used in these simulations, and it is impoltant to have them in mind when analyzing the results. The simulations did not involve transport properties and carry the implicit assumption of the same overall heat transfer coefficient. Algorithms for transport properties for most of the fluids were not available in a form suitable for simulation at the time of the study. Only at the time of finishing up this report, we could compile the values for liquid thermal conductivity and viscosity (the most influential transport properties), and these are given in Appendix $C$. These values, in conjunction with Figures 3 and 4, may be used to estimate if a given candidate fluid offers more promise than is indicated by the simulation results. 

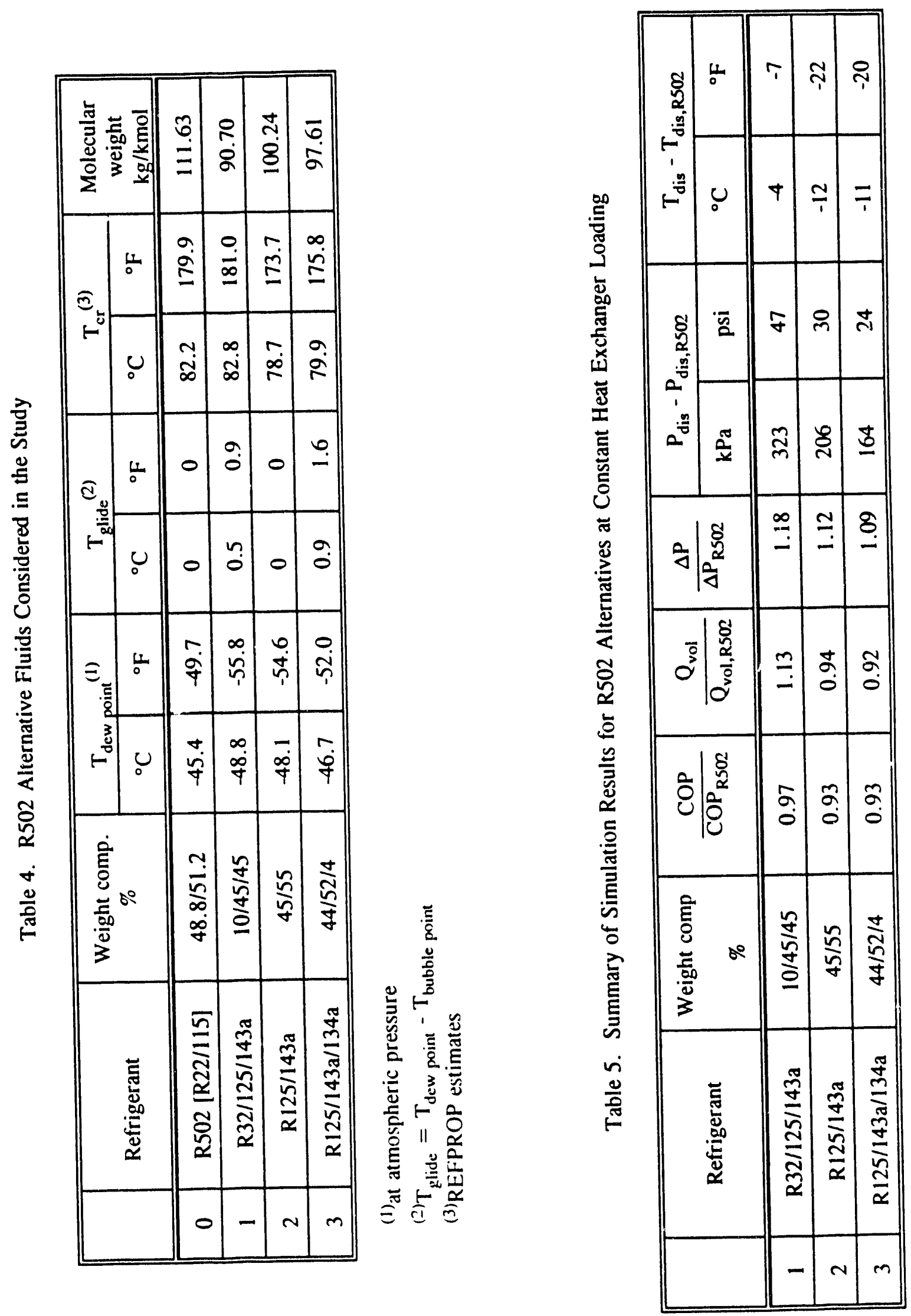
Transport properties may also be used to explain the difference between the simulated COP of propane (lower than that for R22) and the experimental COP reported by Treadwell (10) (higher than the COP for R22). Propane's thermal conductivity of liquid and vapor is somewhat better than that of R22; however, it can be estimated that a significantly better, almost 50 lower, liquid viscosity of propane is responsible for approximately 4.5 percent of difference in the coefficient of performance.

Among other assumptions imposed during simulations, it is important to remember that the evaporator and condenser were represented as pure cross-flow heat exchangers. This implies that the simulations were conservative for zeotropic mixtures if application of counter-flow evaporator and condenser is anticipated; on the other hand, the simulation results are too optimistic for a system using flooded shell-and-tube heat exchangers.

\section{COMPLIANCE WITH AGREEMENT}

This report complies fully with the contract agreement.

\section{PRINCIPAL INVESTIGATORS EFFORT}

This study was carried out by the principal investigators with 80 percent of the effort contributed by P.A. Domanski and 20 percent by D.A. Didion.

\section{REFERENCES}

1. CFR, Code of Federal Regulations, Title 10, Part 430, Washington, DC, 1992.

2. Domanski, P.A., Didion, D.A., and Doyle, J.P., "Evaluation of Suction Line Liquid Line Heat Exchange in the Refrigeration Cycle", Proceedings of 1992 Int. Refrig. Conf. - Energy Efficiency and New Refrigerants, Purdue Univ., West Lafayette, IN, July 14-17, 1992.

3. Domanski, P.A., and Didion, D.A., "Impact of Refrigerant Property Uncertainties on Prediction of Vapor Compression Cycle Performance", NBSIR 86-3373, National Institute of Standards and Technology, Gaithersburg, MD, December 1987.

4. McLinden, M.O. and Radermacher, R., "Methods for comparing the performance of pure and mixed refrigerants in the vapour compression cycle", Int. $J$. Refrig., Vol. 10, p. 318, November 1987.

5. Domanski, P.A. and McLinden, M.O., "A simplified cycle simulation model for the performance rating of refrigerants and refrigerant mixtures", Int. J. Refrig., Vol. 15, No. 2, 1992.

6. Pannock, J., Didion, D.A., and Radermacher, R., "Performance Evaluation of Chlorine Free Zeotropic Mixtures in Heat Pumps - Computer Study and Tests", Proceeding of 1992 Int. Refrig. Conf. - Energy Efficlency and New Refrigerants, Purdue Univ., West Lafayette, IN, July 14-17, 1992.

7. Gallager, J., McLinden, M.O., Morrison, G., Huber, M., and Ely, J., NIST Thermodynamic Properties of Refrigerants and Refrigerant Mixtures Database (REFPROP, Version 3.0), NIST Standard Data Base 23, National Institute of Standards and Technology, Gaithersburg, MD, 1992. 
8. Morrison, G., private communications, National Institute of Standards and Technology, Gaithersburg, MD, 1992.

9. Moldover, M., "An Improved CSD-type Equation of State for Polar Fluids", Presentation at the 1992 Int. Refrig. Conf. - Energy Efficlency and New Refrigerants, Purdue Univ., West Lafayette, IN, July 14-17, 1992.

10. Treadwe11, D., "Application of Propane (R290) to a Single Packaged Unitary Air-Conditioning Product", Proceedings of the CFC and Halon Alternatives Conference, p. 348, Deccmber 3-5, Baltimore, MD, 1991. 


\section{APPENDIX B}

\section{DESCRIPTION OF CYCLE-11 SIMULATION MODELS}

The original CYCLE-11 model (later referred to as CYCLE-11.DT) is described in [5]. It identifies from 5 up to 11 key locations in a refrigeration system; the eleven-point cycle is applicable if a four-point representation of the compressor and a liquid-1ine/suction-line heat exchanger are used, as shown in Figures Al and $\mathrm{A} 2$. In the four-point simulation of the compressor, heat transfer and pressure drop at the suction and discharge valves (locations 1-2 and 3-4) can be accounted for by assigning heat loss end pressure drop parameters, as opposed to a "black box" approach where thes" losses can be lumped together within an overall compressor efficiency.

CYCLE-11 models perform simulations at specified inlet and outlet temperatures of the heat transfer fluids (HTFs) at the eveporator and condenser. In CYCLE11.DT, the evaporator and condenser are represented by temperature differences between refrigerant and HTF, $\Delta T_{0}$ and $\Delta T_{c}$, which are input data. Thus, $\Delta T_{0}$ and $\Delta T_{c}$ have to be known, and this is not always the case if simulations are to be performed at different operating conditions ( $\Delta T_{\text {, }}$ and $\Delta T_{c}$ change since capacity changes with operating conditions).

CYCLE-11. UA relieves us from the need of knowing $\Delta T_{\text {. }}$ and $\Delta T_{c}$ at all conditions. The evaporator and condenser are represented by the product of their overall heat transfer coefficient and area, $U A_{*}$ and $U A_{c}$, which are the input instead of $\Delta T_{0}$ and $\Delta \mathrm{T}_{\mathrm{c}}$.

Regardless of different input requirements, CYCLE-11. UA is amenable to the same convergence logic as CYCLE-11.DT. It is possible because, if we assume that the overall heat transfer coefficient does not change with operating conditions, then $\mathrm{UA}_{0}$ and $\mathrm{UA}_{c}$ stay constant, and since

$$
Q=U A \cdot \Delta T \text { or } \Delta T=\frac{Q}{U A} \text {. }
$$

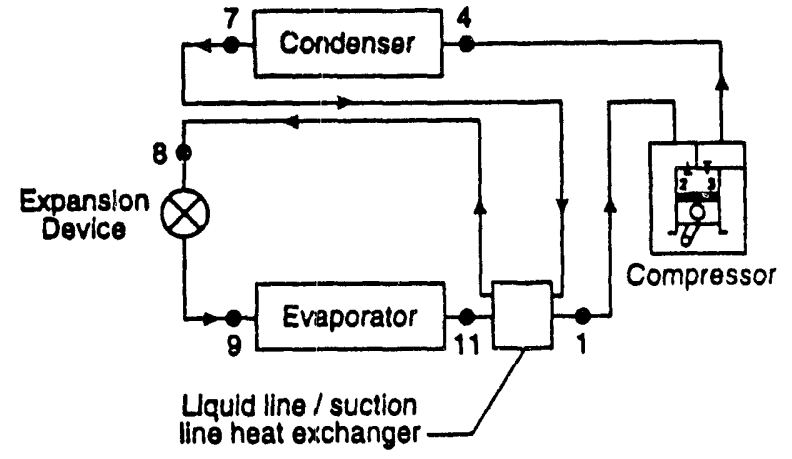

Figure B1. Schematic of a heat pump with a 11sl-hx

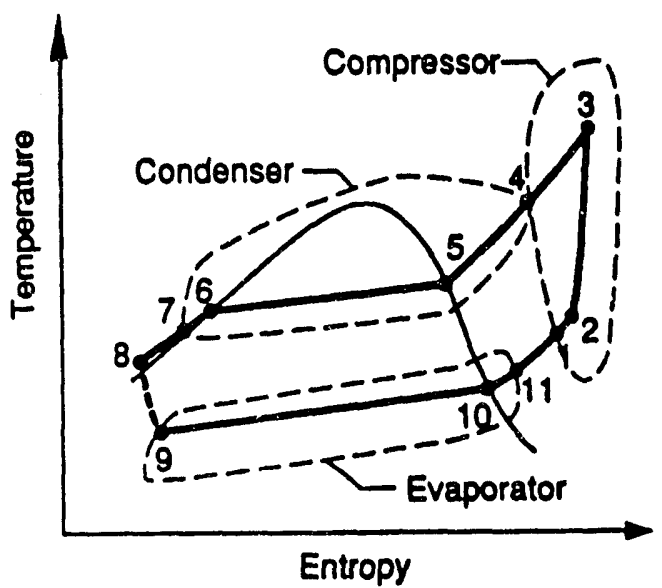

Figure B2. Temperature-entropy diagram for a heat pump with $11 s 1-h x$ working with zeotropic blend 
and capacity (Q) can be calculated from the refrigerant mass flow rate and enthalpy change in the heat exchanger, $\Delta T$ can be calculated and the program will converge in the same manner as in CYCLE-11.DT.

Still another version, CYCLE-11.UADT, was used in this study to explicitly obtain the system performance at the $35^{\circ} \mathrm{C}\left(95^{\circ} \mathrm{F}\right)$ condition satisfying the following constraints:

$$
\begin{aligned}
\text { (1) } \frac{Q_{\bullet}}{U A_{\bullet}+U A_{c}} & =\text { const }=\text { value for } R 22 \\
\text { (2) } T_{\bullet, \text { ave }} & =\text { const }=\text { value for } R z 2
\end{aligned}
$$

The second constraint is synonymous with specifying the same $\Delta T$. since each fluid worked with the same remperature profile of the HTFs in the evaporator.

Considering that $Q-U A \cdot \Delta T$, we may rearrange the first coinstraint as follows:

$$
\frac{U A_{\bullet}+U A_{c}}{Q_{\bullet}}=\frac{1}{\Delta T_{\bullet}}+\frac{Q_{c}}{Q_{\bullet}} \frac{1}{\Delta T_{c}}
$$

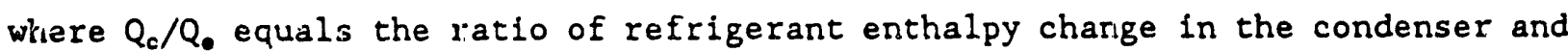
evaporator. The $Q_{c} / Q_{\text {e }}$ ratio varies between fluids becaluse of their different ourlines of the two-phase dome, but can be calculated diring simulation. Knowing $Q_{c} / Q_{0}, \Delta T_{0}$, and the left side of the equation, the first constraint uniquely defines $\Delta T_{c}$, which with $\Delta T_{\text {. }}$ as input allows converging to the solution in a similar way as the DT version of CYCLE-11. 


\section{APPENDIX C}

\section{SELECTED PROPERTIES OF ALTERNATIVE FLUIDS}

The molar heat capacity, thermal conductivity and absolute viscosity are given in Table C-1 and Table C-2 for R22, R502, and their alternative fluids. The values were generated using a not-realized-yet version of REFPROP and should be used with caution.

Table C-1. Selected Properies of R22 Alternative Fluids (evaluated at saturation at $8^{\circ} \mathrm{C}\left(46.4^{\circ} \mathrm{F}\right)$ temperature)

\begin{tabular}{|c|c|c|c|c|c|c|c|c|c|c|c|}
\hline & \multirow[t]{2}{*}{ Refrigerant } & \multirow{2}{*}{$\begin{array}{l}\text { Weight } \\
\text { comp. } \\
\varnothing\end{array}$} & \multirow{2}{*}{$\begin{array}{c}\begin{array}{c}\text { Vapor } \\
\text { heat } \\
\text { capacity }\end{array} \\
J /(\mathrm{mol} \cdot \mathrm{K})\end{array}$} & \multicolumn{2}{|c|}{$\begin{array}{l}\text { Liquid thermal } \\
\text { conductivity }\end{array}$} & \multicolumn{2}{|c|}{$\begin{array}{l}\text { Vapor thermal } \\
\text { conductivity }\end{array}$} & \multicolumn{2}{|c|}{$\begin{array}{l}\text { Liquid } \\
\text { viscosity }\end{array}$} & \multicolumn{2}{|c|}{$\begin{array}{l}\text { Vapor } \\
\text { viscosity }\end{array}$} \\
\hline & & & & $\begin{array}{c}m W / \\
(m \cdot k)\end{array}$ & $\begin{array}{c}\text { Btul } \\
\left(h \cdot f \cdot{ }^{\circ} \mathrm{F}\right)\end{array}$ & $\begin{array}{c}m W / \\
(m \cdot k)\end{array}$ & $\begin{array}{c}\text { Brul } \\
\left(h \cdot f \cdot \cdot{ }^{\circ} F\right)\end{array}$ & $\begin{array}{l}\text { micro- } \\
\text { poise }\end{array}$ & $\mathrm{Ib} /(\mathbf{f t} \cdot \mathbf{h})$ & $\begin{array}{l}\text { micro- } \\
\text { poise }\end{array}$ & $\mathrm{lb} /(\mathrm{f} \cdot \mathrm{h})$ \\
\hline 0 & R22 & 100 & 61.1 & 97.9 & 0.0566 & 9.87 & 0.00571 & 2046 & 0.495 & 121.6 & 0.0294 \\
\hline 1 & $R 32 / 125$ & $60 / 40$ & 63.5 & $i 12.4$ & 0.0650 & 11.54 & 0.00672 & 1913 & 0.463 & 122.3 & 0.0296 \\
\hline 2 & $R 32 / 125 / 134 a / 290$ & $20 / 55 / 20 / 5$ & 82.0 & 83.3 & 0.0482 & 11.67 & 0.00710 & 1982 & 0.480 & 123.9 & 0.0230 \\
\hline 3 & $R 32 / 125 / 134 a$ & $10 / 70 / 20$ & 90.5 & 76.9 & 0.0444 & 11.50 & 0.00665 & 2082 & 0.504 & 123.7 & 0.0229 \\
\hline 4 & R290 & 100 & 78.5 & 99.97 & 0.0577 & 16.05 & 0.00928 & 1165 & 0.282 & 79.9 & 0.0193 \\
\hline 5 & $\mathrm{R} 32 / 125 / 134 \mathrm{a}$ & $30 / 10 / 60$ & 70.5 & 106.5 & 0.0616 & 11.20 & 0.00648 & 2358 & 0.570 & 116.7 & 0.0283 \\
\hline 6 & R32/227ea & $35 / 65$ & 81.3 & \multicolumn{8}{|c|}{ not available } \\
\hline 7 & $R 32 / 134 a$ & $30 / 70$ & 69.6 & 109.5 & 0.0633 & 11.19 & 0.00647 & 2427.2 & 0.587 & 115.5 & 0.0279 \\
\hline 8 & R32/134a & $25 / 75$ & 71.9 & 106.5 & 0.0616 & 11.17 & 0.00645 & 2470.7 & 0.598 & 115.2 & 0.0288 \\
\hline 9 & R134a & 100 & 87.2 & 88.5 & 0.0512 & 11.37 & 0.00657 & 2593.7 & 0.627 & 113.2 & 0.0274 \\
\hline
\end{tabular}

Table C-2. Selected Properies of R502 Alternatives Fluids (evaluated at saturation at $-25^{\circ} \mathrm{C}\left(-13^{\circ} \mathrm{F}\right)$ temperature)

\begin{tabular}{|c|c|c|c|c|c|c|c|c|c|c|c|}
\hline & \multirow[t]{2}{*}{ Refrigerant } & \multirow{2}{*}{$\begin{array}{l}\text { Weight } \\
\text { comp. } \\
\Phi_{0}\end{array}$} & \multirow{2}{*}{$\begin{array}{c}\begin{array}{c}\text { Vapor } \\
\text { heat } \\
\text { capacity }\end{array} \\
J /(\text { mol-K })\end{array}$} & \multicolumn{2}{|c|}{$\begin{array}{l}\text { Liquid thermal } \\
\text { conductivity }\end{array}$} & \multicolumn{2}{|c|}{$\begin{array}{l}\text { Vapor thermal } \\
\text { conductivity }\end{array}$} & \multicolumn{2}{|c|}{$\begin{array}{l}\text { Liquid } \\
\text { viscosity }\end{array}$} & \multicolumn{2}{|c|}{$\begin{array}{l}\text { Vapor } \\
\text { viscosity }\end{array}$} \\
\hline & & & & $\begin{array}{c}m W / \\
(m \cdot K)\end{array}$ & $\begin{array}{c}\text { Blul } \\
\left(h \cdot f \cdot{ }^{\circ} \mathrm{F}\right) \\
\end{array}$ & $\begin{array}{c}m W / \\
(m \cdot K)\end{array}$ & $\begin{array}{c}\text { Btul } \\
\left(\mathrm{h} \cdot \mathrm{ft} \cdot{ }^{\circ} \mathrm{F}\right)\end{array}$ & $\begin{array}{c}\text { micro- } \\
\text { poise }\end{array}$ & $\mid b /(f \cdot h)$ & $\begin{array}{c}\text { micro- } \\
\text { poise }\end{array}$ & $\mathrm{b} /(\mathrm{ft} \cdot \mathrm{h})$ \\
\hline 0 & R502 [R22//IS] & $48.8 / 51.2$ & 71.3 & 83.3 & 0.0481 & 7.9 & 0.00457 & 2911 & 0.704 & 106.4 & 0.0257 \\
\hline 1 & $\mathrm{R} 32 / 125 / 143 \mathrm{a}$ & $10 / 45 / 45$ & 73.8 & 97.7 & 0.0565 & 9.8 & 0.00566 & 2584 & 0.625 & 103.0 & 0.0249 \\
\hline 2 & $\mathrm{R} 125 / 143 \mathrm{a}$ & $45 / 55$ & 81.9 & 89.3 & 0.0516 & 9.9 & 0.00572 & 2481 & 0.600 & 102.7 & 0.0248 \\
\hline 3 & $\mathrm{R} / 25 / 143 \mathrm{~d} / 134 \mathrm{a}$ & $44 / 52 / 4$ & 79.3 & 89.9 & 0.0520 & 9.9 & 0.00572 & 2541 & 0.614 & 102.6 & 0.0248 \\
\hline
\end{tabular}



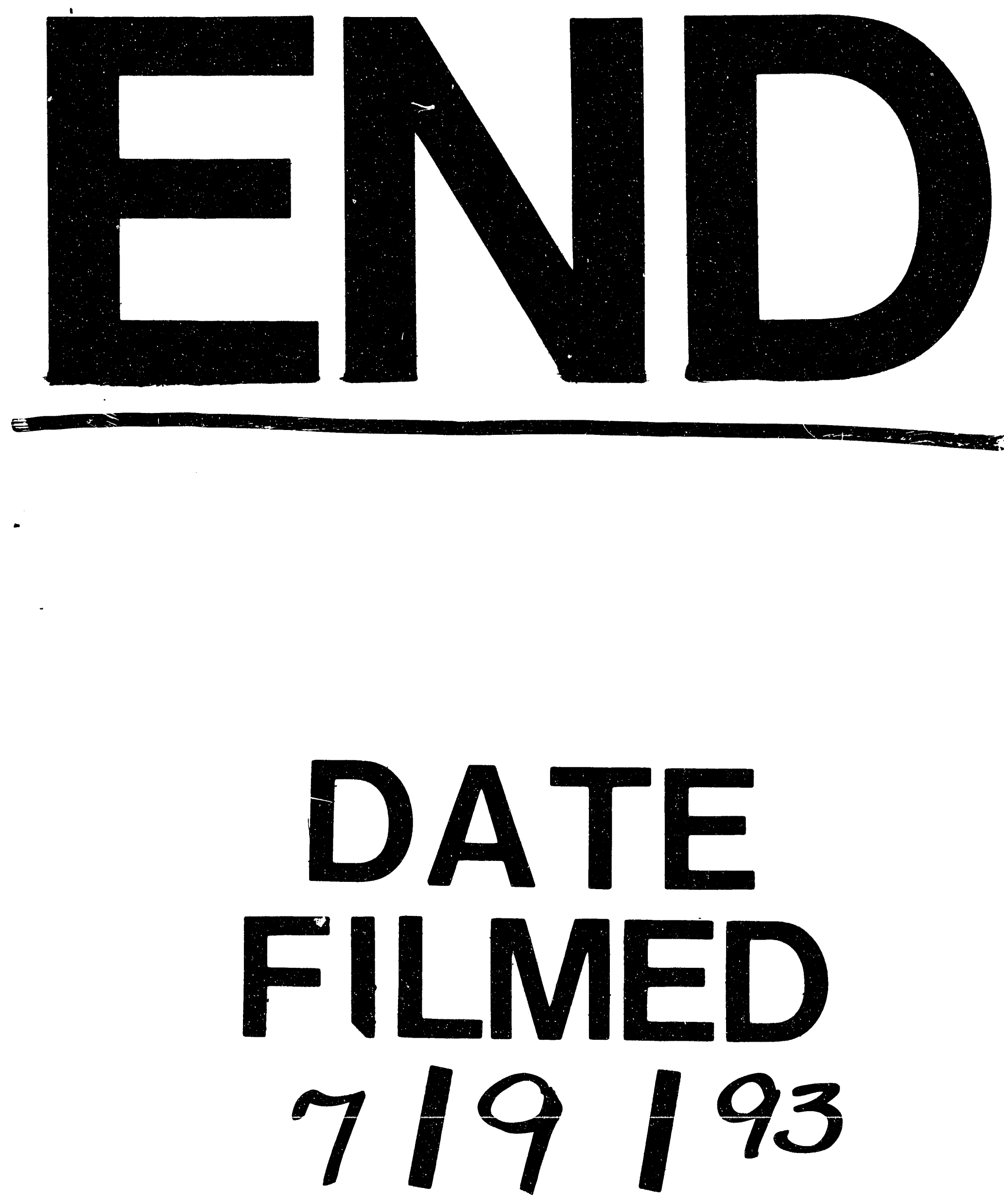
